\title{
Was Working Nation Working?
}

\author{
P.N. Junankar \\ Public Policy Program \\ Australian National University \\ Canberra, ACT 0200 \\ and \\ Cezary A. Kapuscinski \\ ASARC, Economics, RSPAS \\ Australian National University \\ Canberra, ACT 0200
}

Please do not quote without the authors' permission.

An earlier version of this paper was presented at the Macro Workshop held at the University of New South Wales (3-4 April, 1997). The paper has benefitted from the comments on our paper at the Workshop, especially from the discussant Nilss Olekalns. We would also like to thank Michael Keating for his helpful comments.

March 1997, Revised May 1997. 


\title{
Was Working Nation Working?
}

\begin{abstract}
After several months of research and consultation the previous Labor government introduced in May 1994 a set of labour market programs targeted at the long term unemployed with its publication of Working Nation. With the new Coalition government taking office in March 1996 we saw the end of Working Nation. Working Nation had a short life: it was born accompanied with a loud fanfare, it was buried quietly. Did Working Nation labour market programs lead to a fall in unemployment and a fall in long term unemployment? This paper attempts to evaluate its success using simple econometric methods on macroeconomic data. Our results suggest that although Working Nation had a very short life it succeeded in helping the long term unemployed: it was a very valuable social experiment which was aborted for political reasons. The Coalition government has apparently lost interest in the long term unemployed: there has been a massive cutback in expenditure on labour market programs and the only plans it has announced to date are the work for the dole scheme for long term unemployed young people. It is hoping that its industrial relations legislation will lead to a miraculous solution to the problem of unemployment and long term unemployment which has plagued most of the OECD economies for several years.
\end{abstract}




\section{Was Working Nation Working?}

\section{Introduction}

After several months of research and consultation the former Labor government introduced a set of labour market programs targeted at the long term unemployed in May 1994 with its publication of Working Nation. With the new Coalition government taking office in March 1996 we saw the end of Working Nation. Working Nation had a short life: it was born accompanied with a loud fanfare, it was buried quietly. Did Working Nation labour market programs lead to a fall in unemployment and a fall in long term unemployment? This paper attempts to evaluate its success using simple econometric methods on macroeconomic data. Our results suggest that although Working Nation had a very short life it succeeded in helping the long term unemployed: it was a very valuable social experiment which was aborted for political reasons. The Coalition government has apparently lost interest in the long term unemployed: there has been a massive cutback in expenditure on labour market programs ${ }^{1}$ and the only plans it has announced to date are the work for the dole scheme for long term unemployed young people. It is hoping that its industrial relations legislation will lead to a miraculous solution to the problem of unemployment and long term unemployment which has plagued most of the OECD economies for several years.

\section{Trends in Unemployment and Long Term Unemployment}

There has been a rapid growth in Unemployment (U) and Long Term Unemployment (LTU) since the last recession, and although there has been a significant reduction since 1993 this now seems to have stalled. Long term unemployment is nowadays usually defined as people with a continuous spell of unemployment of twelve months or more. Very long term unemployment is sometimes defined as those with duration of two years or more. Since Working Nation defined a new target group of those with unemployment duration of eighteen months or more, we need to consider this group who we shall call Long Term Unemployed-Working Nation (LTU-WN). In studying unemployment and long term unemployment it is important to notice that there are large inflows and outflows into unemployment and into long term unemployment.

Recent unemployment experience, see Figure 1, shows that there was a huge increase in unemployment and long term unemployment after the recession of 198182 and again after the recession of the early nineties. Although unemployment rates have fallen in recent years they are still above the previous trough and there is some evidence that unemployment is rising again, or at best has plateaued.

\footnotetext{
1 In the 1996-97 Budget expenditure on Labour Market Programs was reduced by $\$ 575$ million in 1996-97 and by $\$ 956$ million in 1997-98, see Budget Statements 1996-97, Budget Paper No. 1, Table 4, p. $1-18$.
} 
Figure 2 presents a profile of the standard LTU (duration of unemployment over 52 weeks), the LTU which is the target of the Working Nation (LTU-WN, duration of unemployment over 18 months) and VLTU (duration of unemployment over 2 years). Apart from the obvious differences in the size of these pools of unemployment the only feature worth noting is the difference in peaks. In particular, due to the definition of the series, LTU-WN peaks lag LTU, while VLTU lags both LTU and LTU-WN. It is also interesting to note that the levels of LTU rise rapidly and fall slowly, but never to the previous lower levels. The ratcheting up of unemployment and LTU is a significant feature of many of the OECD countries labour markets. The big increase in LTU after the last recession led to the then Labor Government setting up a committee to study the problem which then led to the Working Nation White Paper.

\section{Figure 1: Unemployment Rates, Males and Females (seasonally adjusted)}

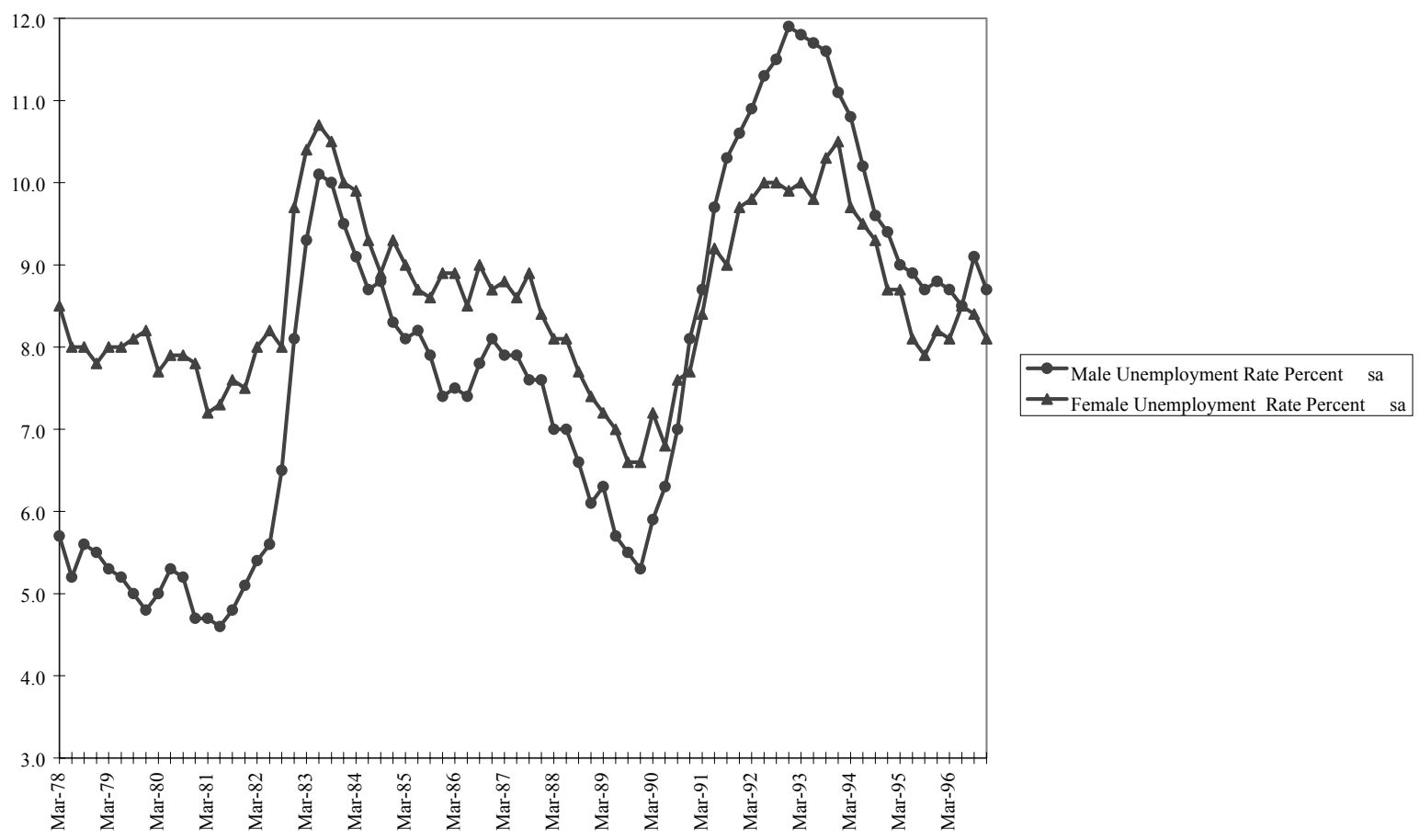

Source: ABS 6203

Figure 2: Long term unemployed: comparison of different durations: persons 


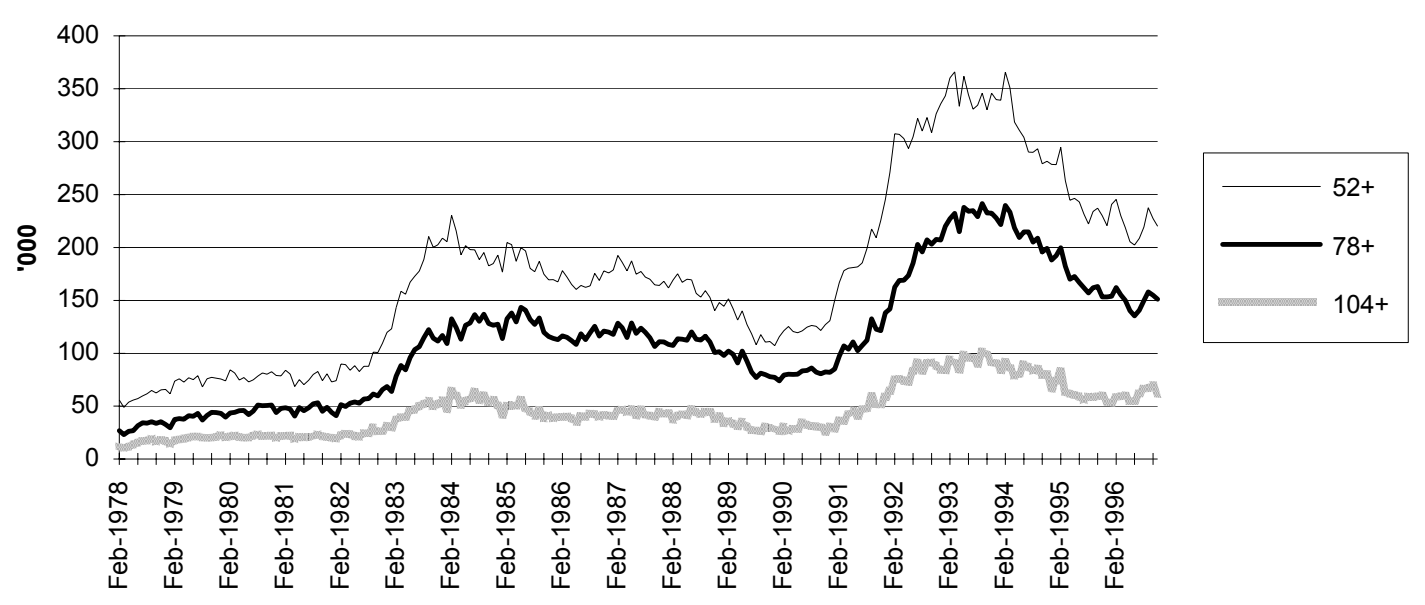

Source: ABS 6203

\section{Working Nation: The Policy Package}

The main features of the Working Nation White Paper included a big expansion in labour market programs (LMPs), case management of the unemployed, a Youth Training Initiative, training wages for all trainees (including adults), New Work Opportunities (ie direct job creation), the Job Compact, and changes to the social security system. Any person who had been on unemployment allowances for over 18 months would be offered a (mainly) full time job (for at least 12 months), mainly in the private sector. This would involve subsidies to employers, "encouragement and moral suasion" (to be supervised by NETTFORCE), and case management (to be supervised by the Employment Services Regulatory Agency, ESRA) to make the unemployed "job ready". The Job Compact participant would have to "accept any reasonable job offer", and would have a case management officer, a "minder".

One new feature (which one of us had recommended to the European Community ages ago, see Junankar (1988)) is the targeting of labour market programs to those who are likely to become long term unemployed (the disadvantaged). As previous work has shown, see Chapman, Junankar and Kapuscinski (1993), growth of the economy is not sufficient to decrease long term unemployment (LTU). It is necessary to introduce targeted labour market programs.

Particularly notable features of this policy were the reciprocal obligations and case management for unemployed people. A significant policy innovation was the use of non-government agencies to deliver case management, monitored by ESRA.

This was an important new policy and a significant difference from the European Union countries (or the European Union White Paper) was the emphasis on LTU and those likely to become LTU. 
Public Policy Issues: Targeting of Unemployment (U) and LTU for efficiency, equity and social reasons. Active Labour market programs usually include an element of training which helps the unemployed to find work. In addition, due to problems of skill decay, loss of interest in job search, and employers treating the long term unemployed as "unemployable" once unemployment rises it does not fall easily. This concept of hysteresis suggests that there are efficiency gains of labour market programs ${ }^{2}$. In addition there are equity reasons for labour market programs: to provide a fair go for workers. Even if labour market programs only led to a redistribution of unemployment it would still have an element of equity (sharing the burden of unemployment) and also an efficiency aspect since it would have prevented skill decay ${ }^{3}$.

The new policy package was introduced in May 1994, at a time when unemployment and long term unemployment had just begun falling and then continued to fall rapidly.

Question: To what extent is fall in Unemployment and long term unemployment due to policy?

There was a decrease in funding for Working Nation in the Budget of 1995-96 because of a growth of employment and a decrease in unemployment, but also because of the government being under pressure to lower the budget deficit. The 1995-96 budget cut expenditure on Labour Market Programs by $\$ 348$ million in 1995-96, (Budget Statements 1995-96, Budget Paper No. 1, p. 1-2). There were some revisions to policy in the Crean Statement dated 19th October 1995. This consisted of mainly repackaging of subsidies etc.and a greater emphasis on training rather than wage subsidies.

With the election of the Coalition Government in March 1996 Working Nation labour market programs were buried, with a significant decrease in expenditures on labour market programs announced in its 1996 budget. In the 1996-97 Budget expenditure on Labour Market Programs was reduced by a further $\$ 575$ million in 1996-97 and by $\$ 956$ million in 1997-98,(see Budget Statements 1996-97, Budget Paper No. 1, Table 4, p. 1-18).

\section{Methods of Evaluating "success" of policies}

Instead of the usual emphasis on the unemployment stock, we prefer to focus on labour market flows and how these are likely to be affected by labour market programs, see Diagram 1. Policies affect demand for labour (by wage subsidies), supply of labour (by improving quality via training), and working of labour market (a leftward shift of the Beveridge curve by providing better information, counselling etc. which should improve the job matching of employers with

\footnotetext{
2 See Piggott and Chapman (1995).

${ }^{3}$ Assuming that skill decay is not linear with time, it is usually assumed to increase at an increasing rate. However, there are no empirical studies of this issue that we are aware of.
} 
vacancies with the unemployed looking for work $)^{4}$. All these policies should lead to a increase in the outflows from unemployment and long term unemployment. It is, of course, definitionally true that if the unemployed are on training or other programs they are not formally unemployed. In labour force surveys these people may or may not refer to themselves as unemployed ${ }^{5}$. The inflows into unemployment would be affected if employers decreased their firing of workers due to improved expectations about demand, fewer workers quit (however, quits usually decrease when the labour market is slack), and new workers join or rejoin the labour market to look for work. The net effect on inflows is ambiguous. The inflows into long term unemployment from short term unemployment would decrease due to labour market programs. Some of this may be simply definitional as those in (say) subsidised employment would no longer be unemployed. If at the end of the program they are not retained they would enter unemployment with a zero duration. Diagram 1 provides a synoptic view of this dynamic process.

The impact of labour market programs on the labour market have to be analysed by answering a set of questions.

\section{Questions:}

(i) Have employment prospects improved for program participants?

(ii) Has unemployment decreased by more than expected due to other changes in economic variables like output and wages? Has LTU decreased by more than expected due to fall in unemployment?

(iii) Has net employment increased?

However, to analyse these questions we need to know what would have occurred in the absence of the Working Nation programs.

Macro: What is the counter-factual?

What would Unemployment and Long Term Unemployment have been in the absence of Working Nation?

Over the past few years there has been a rapid growth in employment, a decline in Unemployment and in long term unemployment. Is this success because of Working Nation?

\section{Diagram 1: Labour Market Stocks and Flows}

\footnotetext{
${ }^{4}$ For an interesting discussion see Calmfors (1994), and Kenyon (1994).

5 See Burgess (1995).
} 


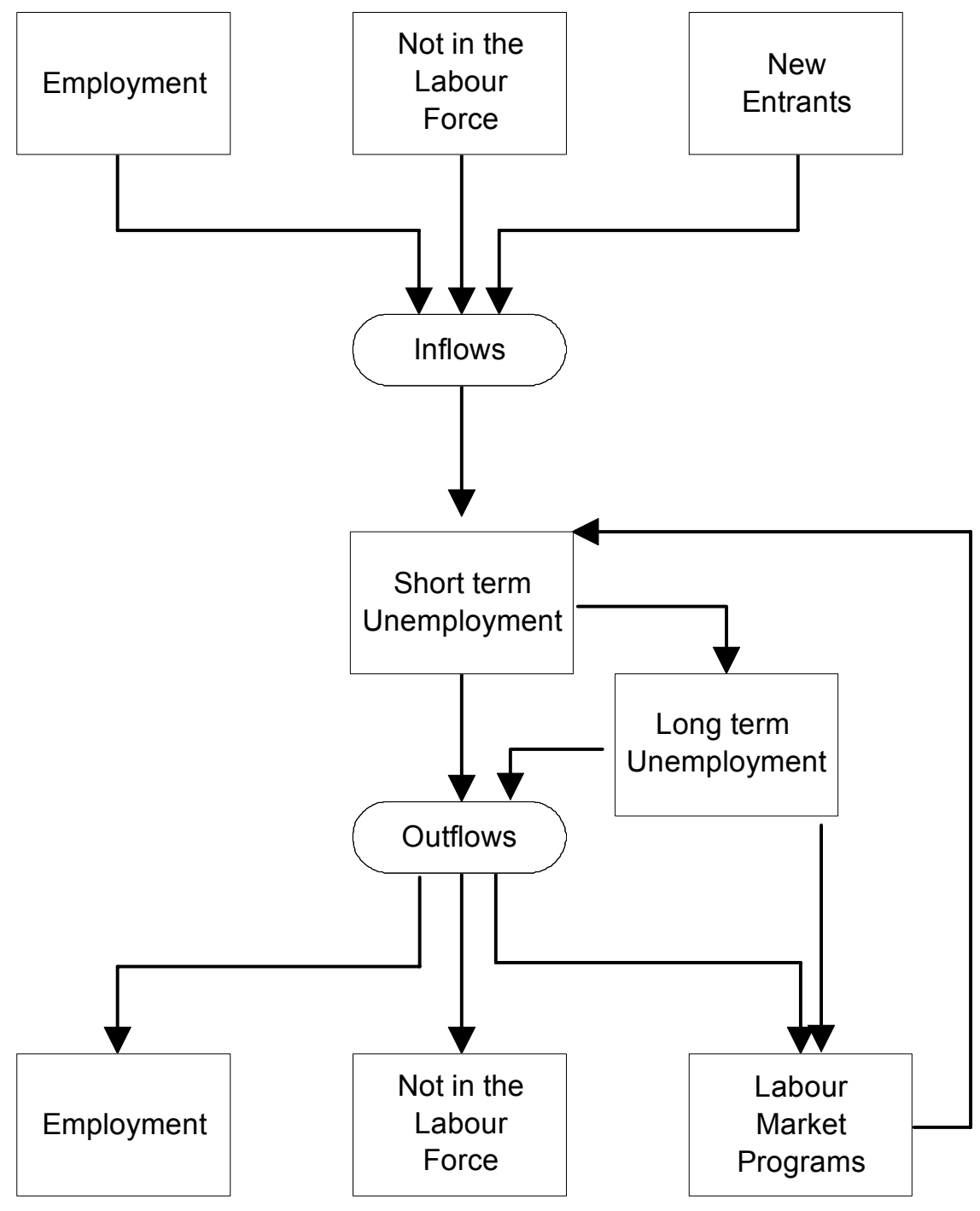

\section{Assessing Labour Market Programs}

Whether subsidies to employers increase employment and decrease unemployment in aggregate depends on several factors: (a) how sensitive employment is to a small change in the wage (ie the elasticity); (b) the extent to which there is deadweight loss (the jobs which would have been created anyway); (c) substitution (the extent to which the target group is helped at the expense of the rest of the unemployed); (d) job displacement (subsidised employers expanding at the expense of nonsubsidised employers); (e) the extent to which these programs increase the labour force participation; and (f) employers attitudes to the qualities of the target groups. The new subsidies being offered are for the employer to hire additional workers and to provide them with training. This would mean that the employers can use the subsidies as a method of screening the long term unemployed at lower 
cost than otherwise. But if there is an excess supply of potential workers, who have not been stigmatised by long term unemployment, why should employers hire the long term unemployed?

The impact of labour market programs that provide subsidised training on employment and unemployment would depend on the extent to which this training increases labour productivity. It is possible for training to simply affect the faces in the unemployment queue: the recently trained person gets a job but someone else in the queue does not. Time series evidence shows that even though the average level of education and training of the workforce has increased it has not solved the unemployment problem. The average level of education of the unemployed has increased over the years. Improved education and training has not, in and of itself, solved the unemployment problem.

\section{Macroeconomic effects}

Various labour market programs that improve the job matching process (eg JobClubs) would decrease the cost to employers of a vacancy and may lead to rightward shift in the labour demand curve, see Calmfors (1994). Similarly, an increase in labour productivity of labour market programs would lead to a rightward shift in the labour demand curve, and ceteris paribus, lead to an increase in employment. Another possible impact of labour market programs is to decrease the number of discouraged workers and hence lead to an increase in the participation rate which may lead to (assuming wages do not adjust rapidly) an increase in the unemployment rate. However, if the increased participation rate increases labour market competition by making the "outsiders" compete with the "insiders" this would lead to increased employment via shifting the wage setting schedule downwards, see Calmfors (1994), OECD (1993).

\section{Microeconomic effects}

To study the microeconomic impact of labour market programs, ideally we would employ micro data using matched samples, or randomised trials. That is we would provide labour market programs to a "treatment group" on a randomised basis and use a matched sample as a "control group". However, there are so called ethical problems: if we think that these labour market programs are effective how can we deny them to some people? These sort of randomised trials are fairly common in medicine where such ethical issues are obviously ignored for the "greater good". There is, however, a recent study in the UK where such a randomised trial was carried out and showed that labour market programs were successful, see Dolton (1996).

Another ideal method would be to use econometric methods on longitudinal data (the ABS, 1995, Survey of Employment and Unemployment Patterns, first results from which were published in Cat. no. 6286.0). Here, we would compare the labour market performance of those who went on labour market programs with other 
labour market participants, while controlling for all other relevant factors. However, the first wave of this data set is just being made available (at a price!).

\section{Evaluation of macroeconomic effects}

However, even if labour market programs are successful in increasing the probability of employment of their clients it does not follow that there is an increase in net employment and/or a decrease in unemployment and long term unemployment. In this paper we assess the macroeconomic impact of labour market programs on unemployment and long term unemployment. We do this firstly by comparing the labour market outcomes of the early eighties recession with that of the early nineties. Secondly, we use simple econometric methods to estimate a model of long term unemployment on a set of data upto the commencement of Working Nation and then forecast outside the sample and compare it with the actual data. If the forecasts are consistently greater than the actual data then we infer that the labour market programs were successful. Finally, we estimate simple employment functions on data upto the commencement of Working Nation and then forecast outside the sample following a similar method to that for long term unemployment.

\section{Labour Government's Evaluation: "All things bright and beautiful"}

In Crean's Report (1995) there was an evaluation of the Working Nation labour market programs, but much of the analysis was superficial. Due to the nearness to the impending general election the report provided a very positive gloss on the labour market achievements:

"Remarkable achievements";... "very strong employment growth, declining unemployment and falling long-term unemployment", p. 2.

"Working Nation has contributed to a marked fall in long term-unemployment of 61,100 or 20.1 percent in the year to June 1995. This reduction is a much better outcome than recorded in the employment recovery of the mid-1980s ... The fall for those unemployed 18 to 24 months, one of the groups most affected by the Job Compact initiatives, has been even greater at around 39 per cent." (p. 4)

Although these evaluation studies show higher probabilities of employment for LMP participants there is a problem of selection bias,"creaming". We need a proper control group.

Employers surveys showed that the long term unemployed were stigmatised by the employers: they were not willing to touch the LTU! (See Crean, p.10 and DEETYA 1996) 


\section{Coalition Government's Evaluation: Thorns on the roses!}

After the Coalition government took office there has been a DEETYA (1996) report (which was set up by the previous government) and a new report entitled The Net Impact of Labour Market Programmes (DEETYA, 1997) ${ }^{6}$.

The 1996 DEETYA report is much more circumspect about the success of the Working Nation programs. It provides evidence that people on labour market programs had an increased probability of employment compared to those who were not on these programs. However, many of those on programs returned to unemployment at the end of the program, and hence appear to have a shorter duration of unemployment. The report also argues that because the Working Nation policies shifted the targeting from the unemployed with less than 18 months to those with greater than 18 months, more people flowed into the 18 months plus target group from the shorter durations (see DEETYA, 1996, p. 51). It finds, not surprisingly, that it is more expensive to help the longer term unemployed than the shorter term unemployed. It also questions the policies of providing a job guarantee to all disadvantaged clients.

It points out that even though labour market programs may help the clients to increase their probability of finding employment it does not necessarily follow that it would increase net employment or decrease the level of unemployment (DEETYA, 1996, p.111).

DEETYA (1997) compares the employment of labour market participants with a matched group of non-participants using data from the Post Programme Monitoring (PPM) survey and matching programme participants records with DSS allowance records. PPM estimates are obtained through a survey conducted 3 months after clients have left programme assisitance. The data are for clients who were on DSS allowance at the start of their placement on a programme and had left assistance during the month of February 1996, and were surveyed during May and June 1996. The statistical methods used are fairly simplistic, namely comparing the means of two groups. Ideally, they should have used econometric methods and estimated a logistic or probit equation and controlled for a set of demographic and educational variables, as well as the duration of unemployment. The study finds that wage subsidy programs (JobStart) was much more successful in increasing their employment than job training programs like JobTrain or SkillShare. However, this is not surprising as the clients for the latter programs were disadvantage jobseekers like the long term unemployed or people with disabilities. Section 4 of this Report provides some cost estimates of each labour market program per client who finds unsubsidised employment. Not surprisingly, JobStart (the wage subsidy program) does well and SkillShare (aimed at the unemployed with disabilities or the long term unemployed) is very expensive.

\footnotetext{
6 The new Coalition Government has not only changed the emphasis and content of labour market programs it has also changed the spelling of Programs to Programmes! There is a new political correctness in Canberra.
} 
This DEETYA analysis, however, assumes that there is a net impact if the probability of employment of a program client is greater than a non-participant. This ignores the possibility of deadweight loss, job substitution, and job displacement effects. To see if there is a net impact of labour market programs there is no alternative to looking at the macro data on employment, unemployment and long term unemployment, see our results below. 


\section{A preliminary analysis of the data}

\section{What is the counter-factual?}

If we assume that the structure of the economy has remained unchanged, we would expect the labour market to behave in the same fashion as when it came out of a previous recession (assuming that other things are equal). Figure 3 shows that the economy came out more rapidly from the 1983 recession than the 1993 recession 7 . If we now compare employment growth as we came out of the nineties recession with that in the previous recession of eighties we can get some impression about the impact of Working Nation programs. Figures 4 and 5 compare employment growth over the two recessions: if we index employment to be 100 in March 1983 and compare it with employment indexed as 100 in March 1993 (the peak of unemployment) we see that male employment growth has done slightly better in coming out of this recession (but getting worse in the last year), while female employment has been weaker especially later on in the recovery ${ }^{8}$. Given that GDP growth was more rapid in the eighties than the nineties it means that employment growth has been relatively much stronger in the upturn from the nineties recession than the eighties recession. (Note, however, that the ABS has recently revised data which suggests that previous data were underestimates). This suggests that Working Nation policies have been more successful for males than for females.

Figure 3: Gross Domestic Product (A) in two cycles, 1983 and 1993

\footnotetext{
7 We have used the bottom of the employment cycle, rather than the bottom of the GDP cycle for these comparisons.

8 See Appendix B for a similar profile for Employed Wage and Salary Earners.
} 


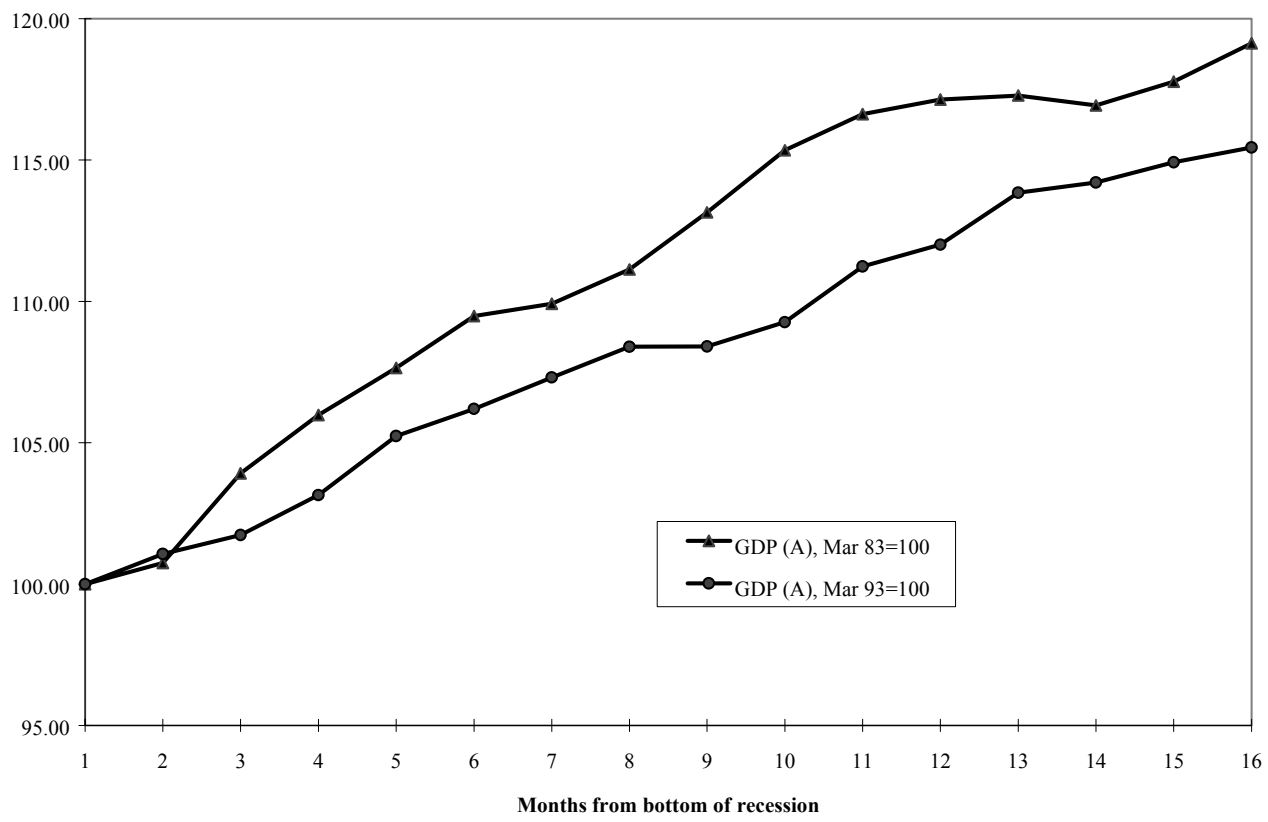

Figure 4: Male Employment Growth in two cycles, 1983 and 1993

Male Employment Growth in two cycles, 1983 and 1993

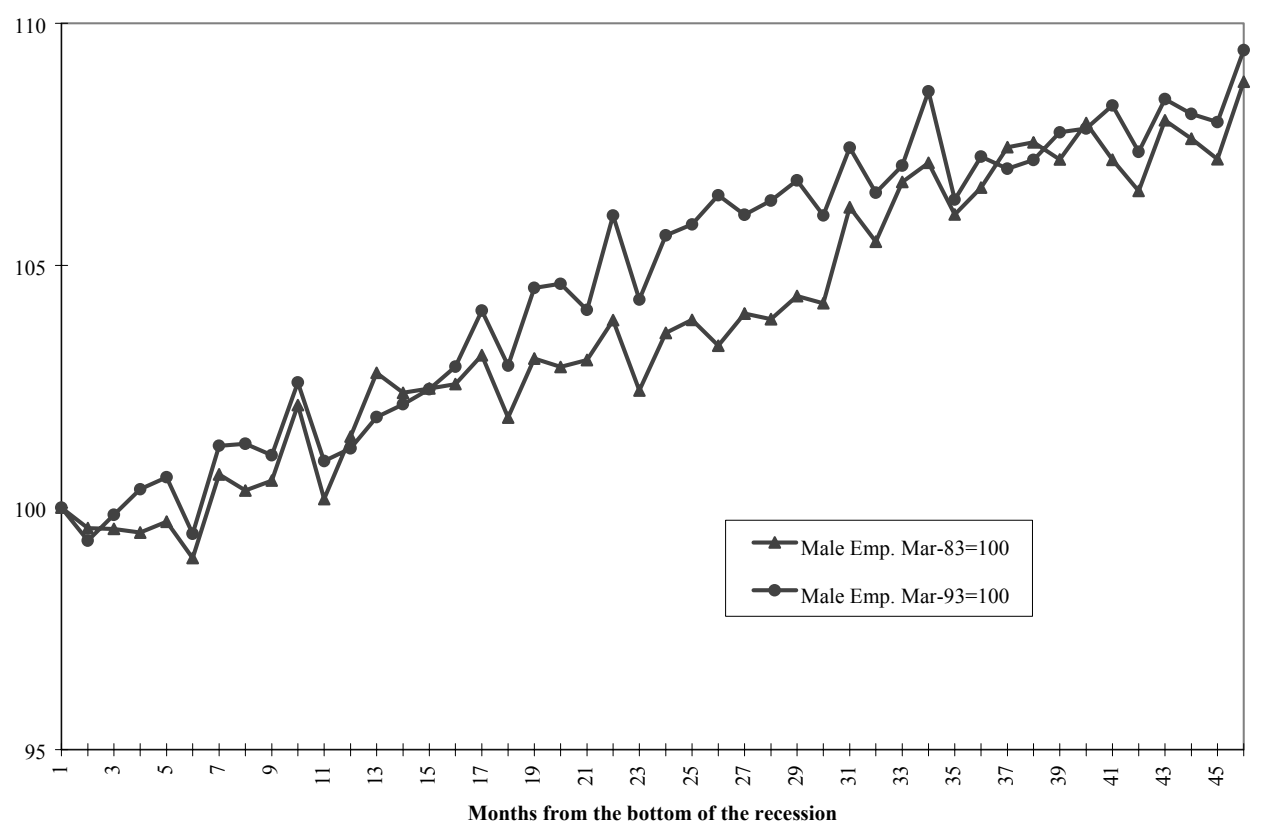

Source: ABS Ausstats. 
Figure 5: Female Employment Growth in two cycles, 1983 and 1993

Female Employment Growth in two cycles, 1983 and 1993

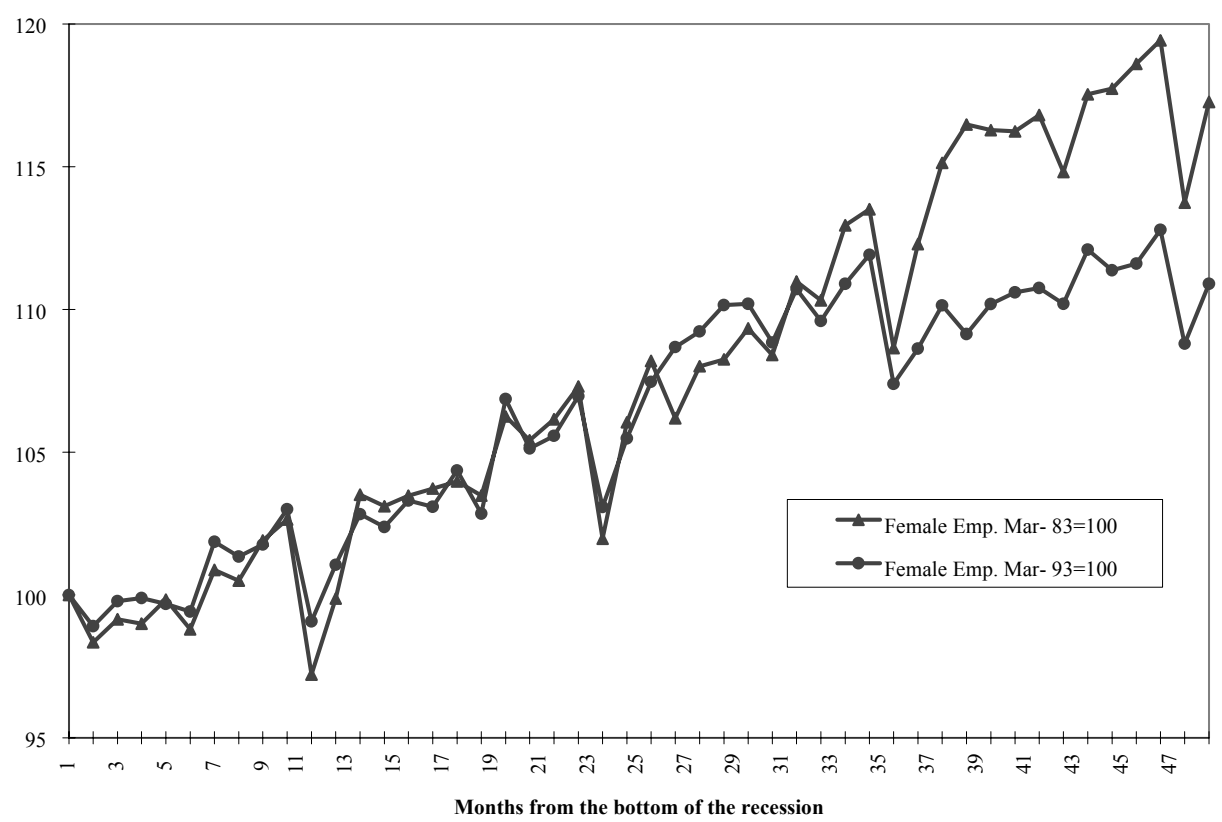

Source: ABS Ausstats.

Figure 6

Male Unemployment Rate in two cycles, 1983 and 1993

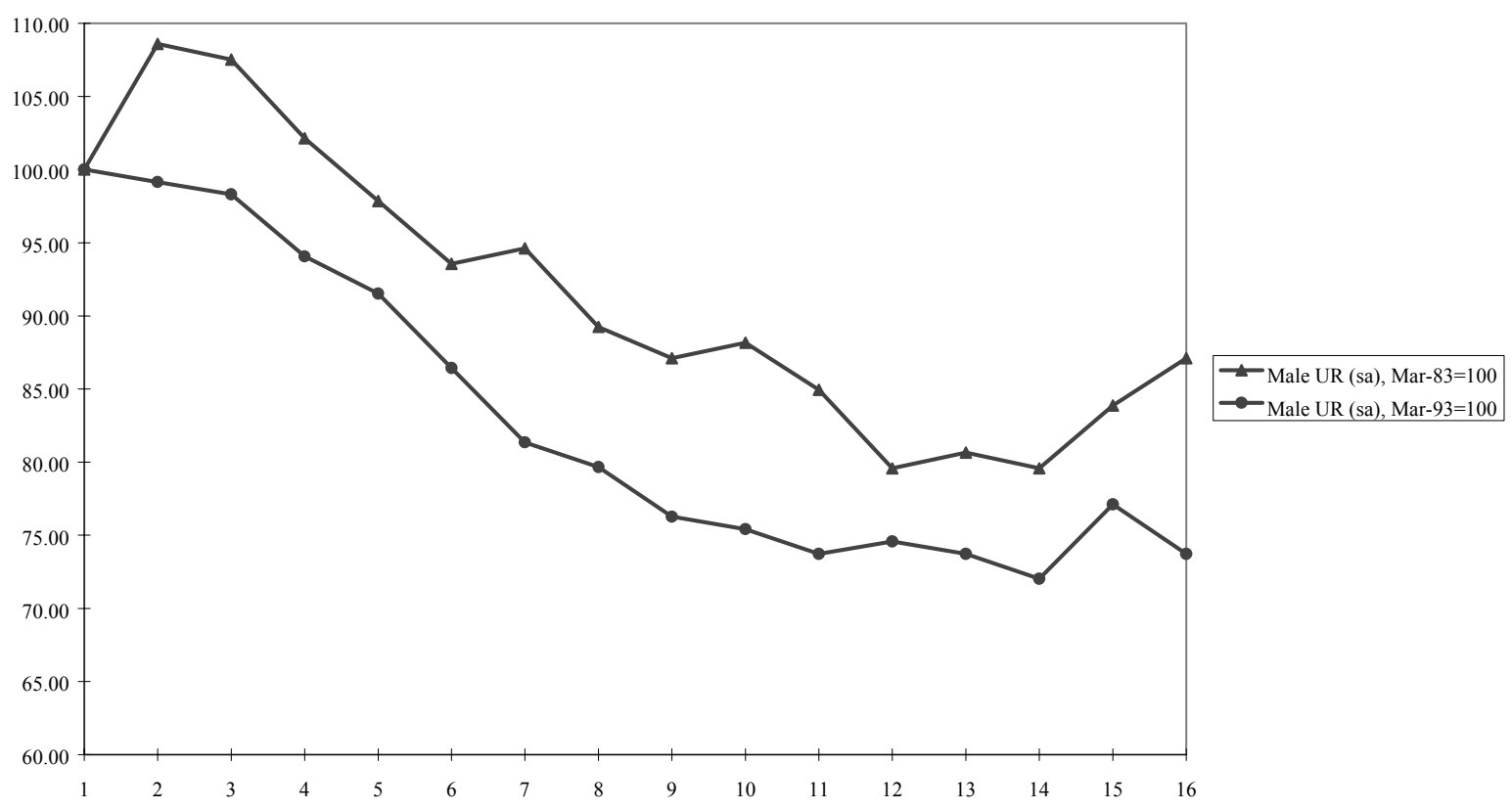

Source: DX data base. 
Figure 7

Female Unemployment in two cycles, 1983 and 1993

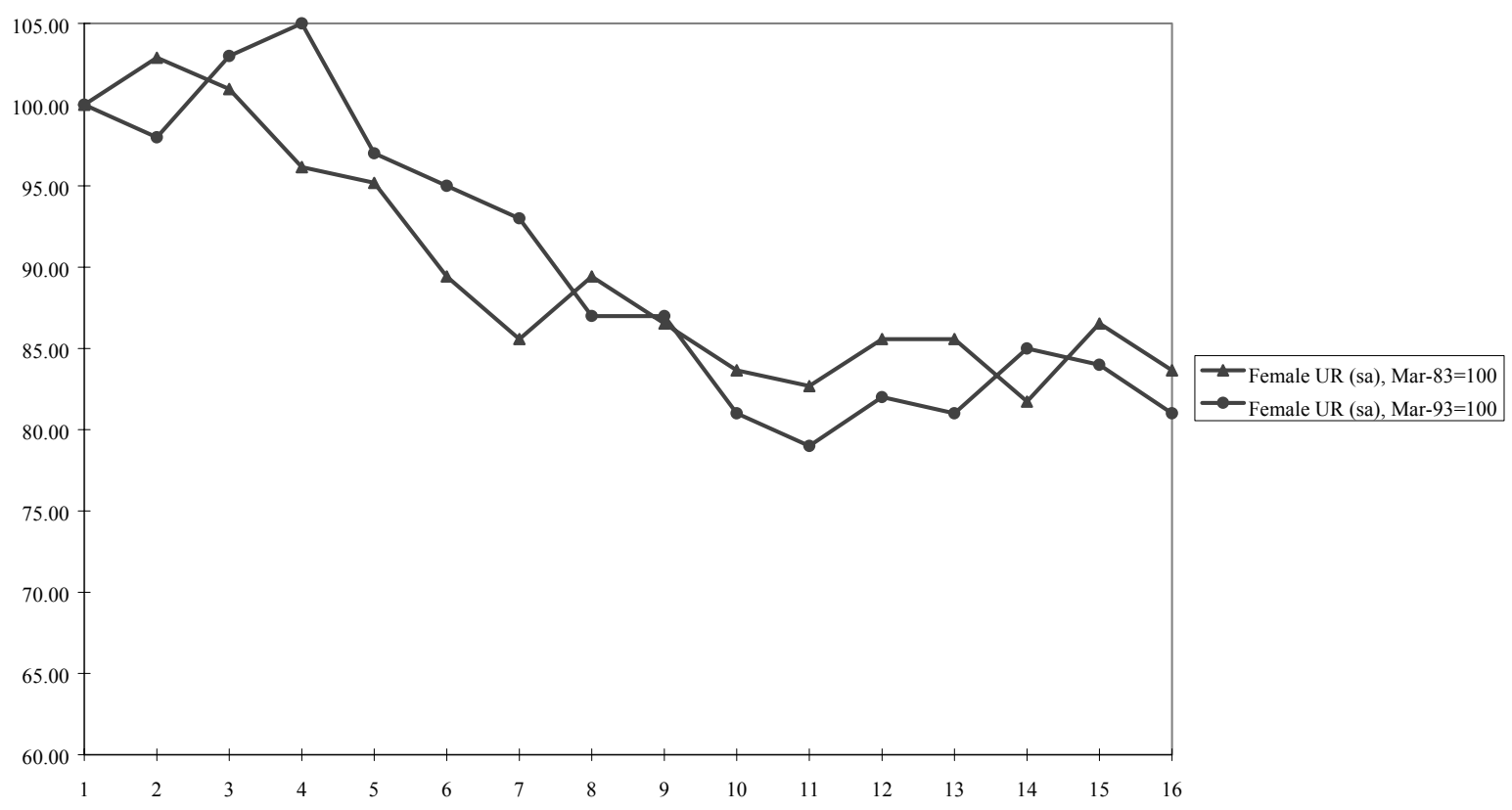

Source: DX data base.

Figure 8

Proportion of LTU-WN, Males

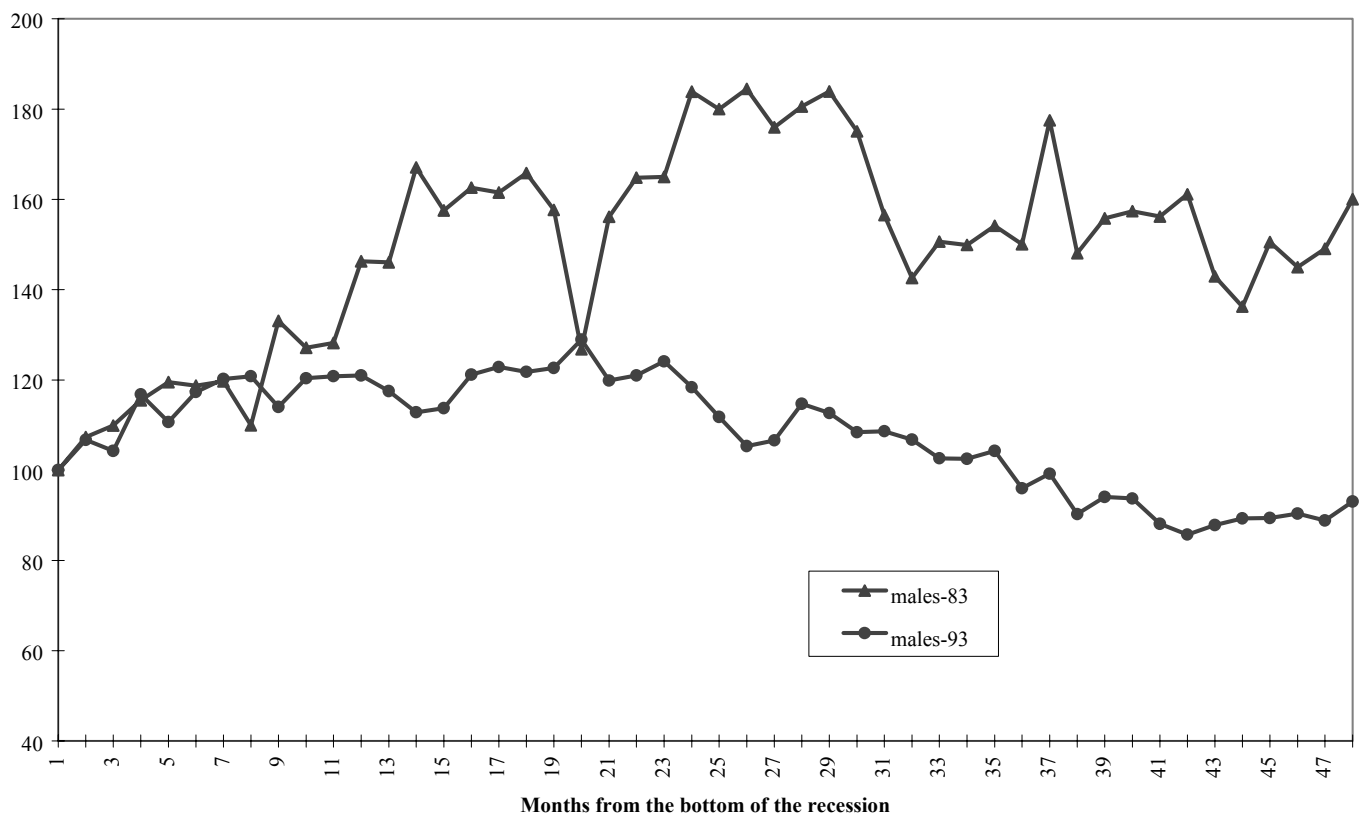

Source: ABS 6203 (unpublished).

Figure 9 


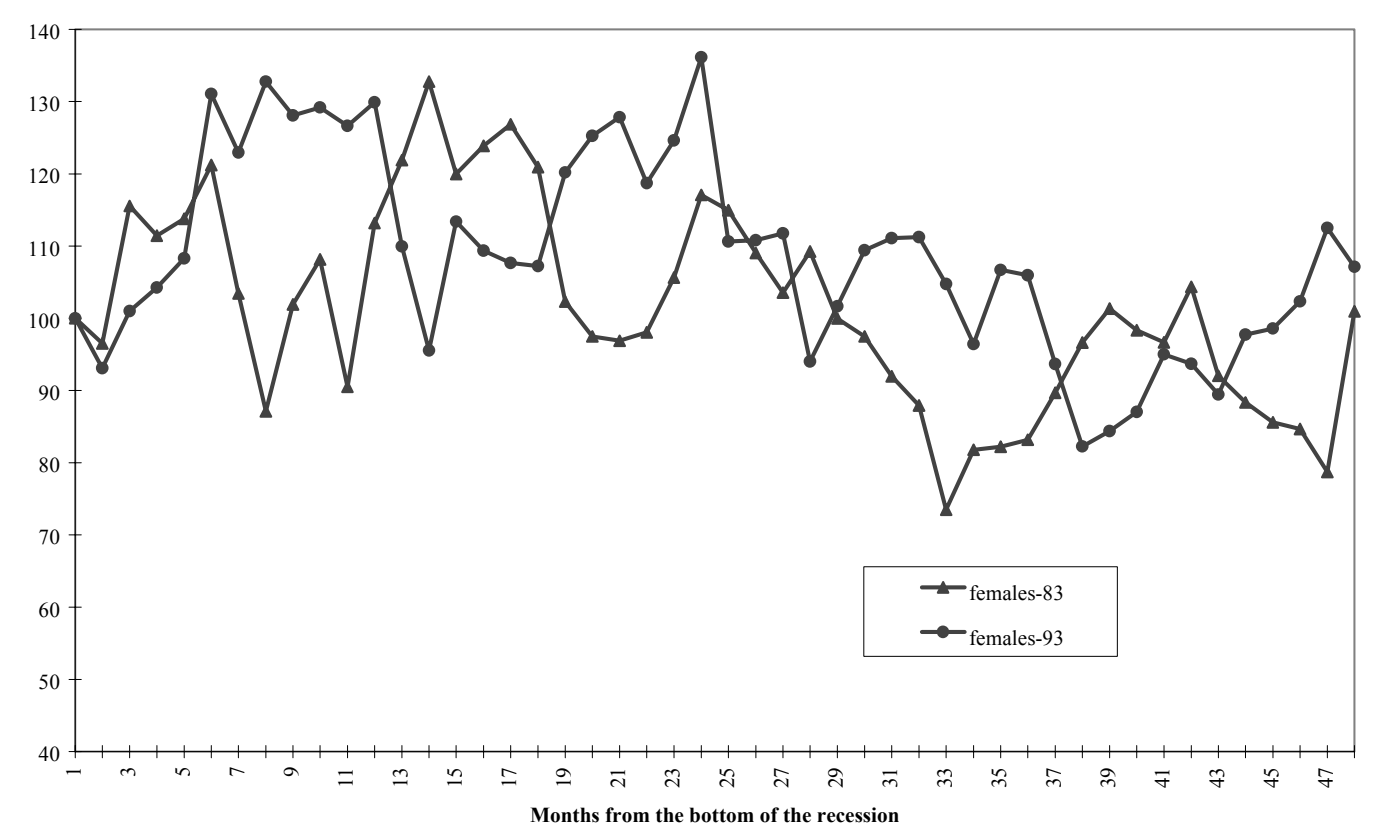

Source: ABS 6203 (unpublished). 
Figure 10

Proportion of LTU-WN in LTU (12+), Males

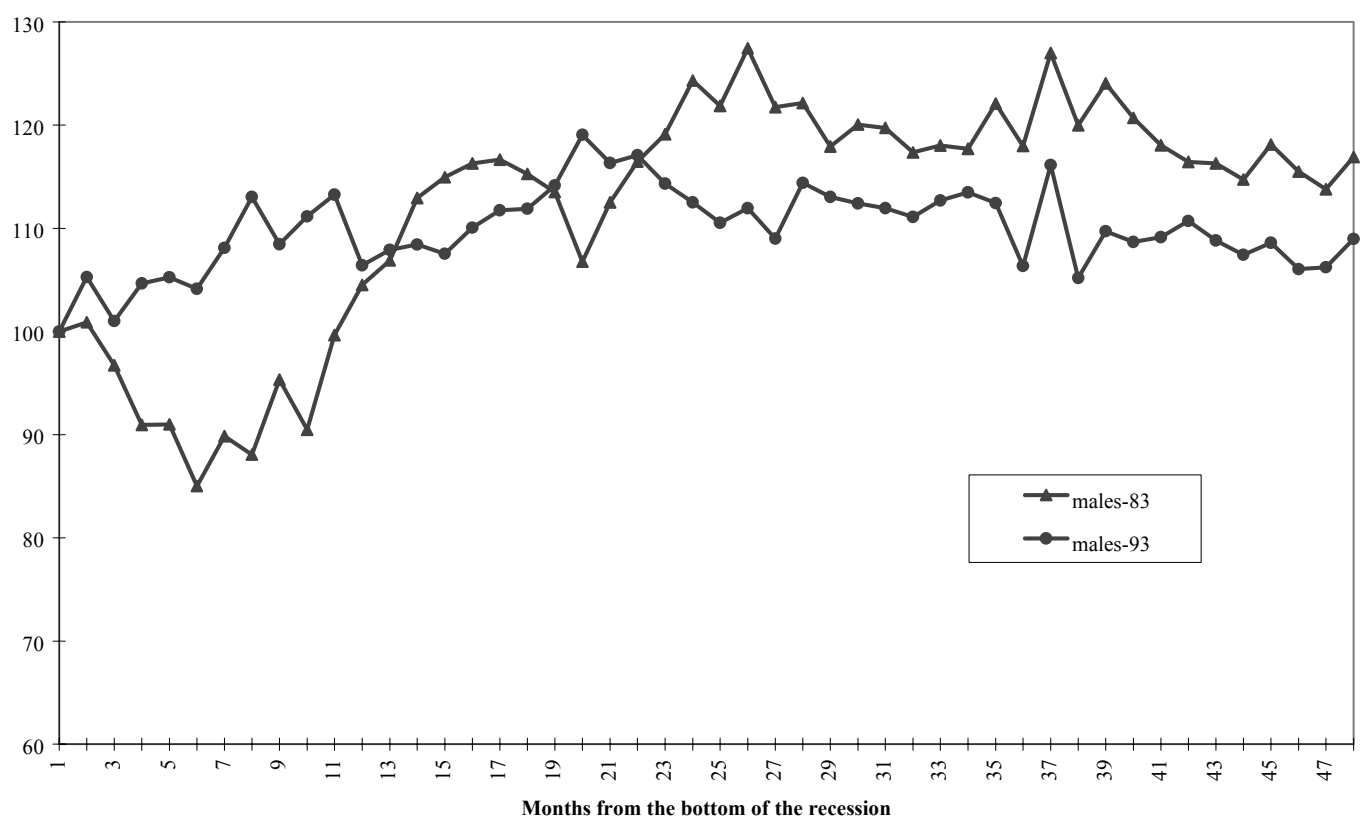

Source: ABS 6203 (unpublished).

Figure 11

Proportion of LTU-Wn in LTU (12+), Females

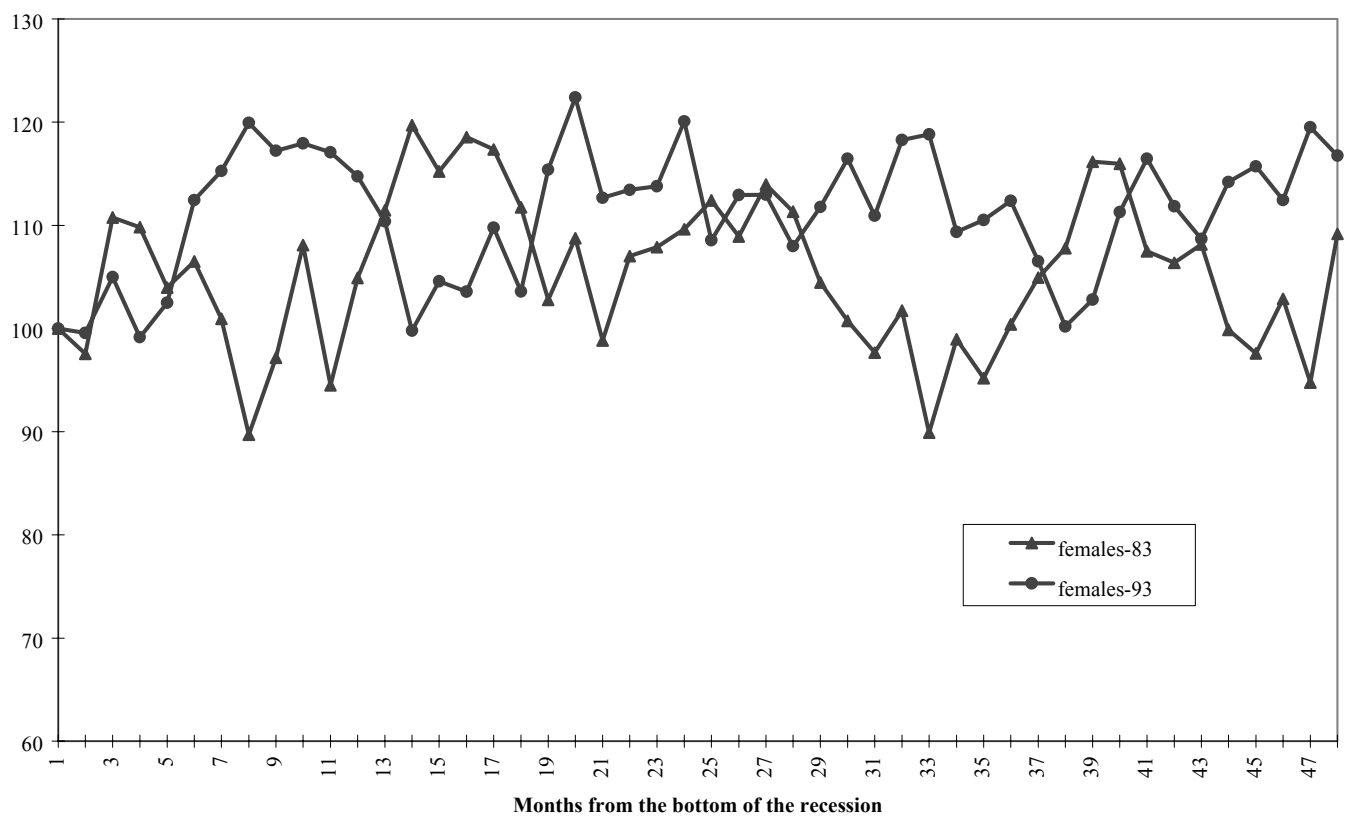

Source: ABS 6203 (unpublished). 
Figure 12

Exit Probability from Unemployment, Persons

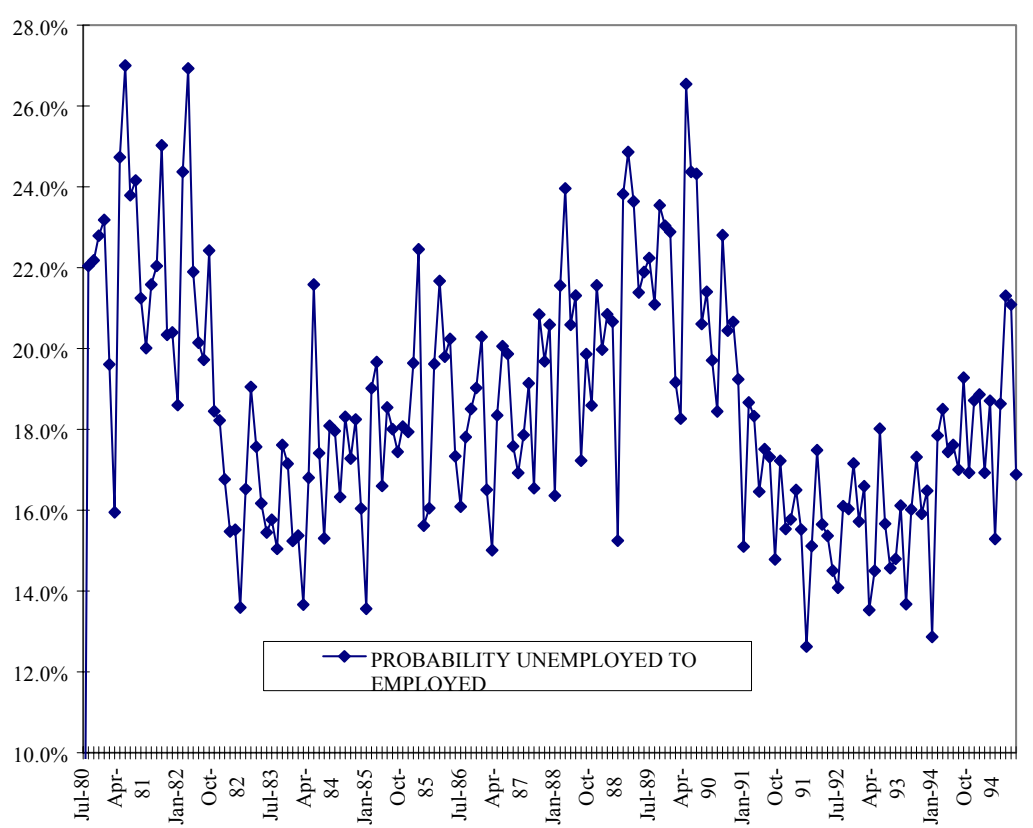

Source: ABS (unpublished).

Figure 13

Exit Probabilities in two cycles, Persons, 1983 and 1993

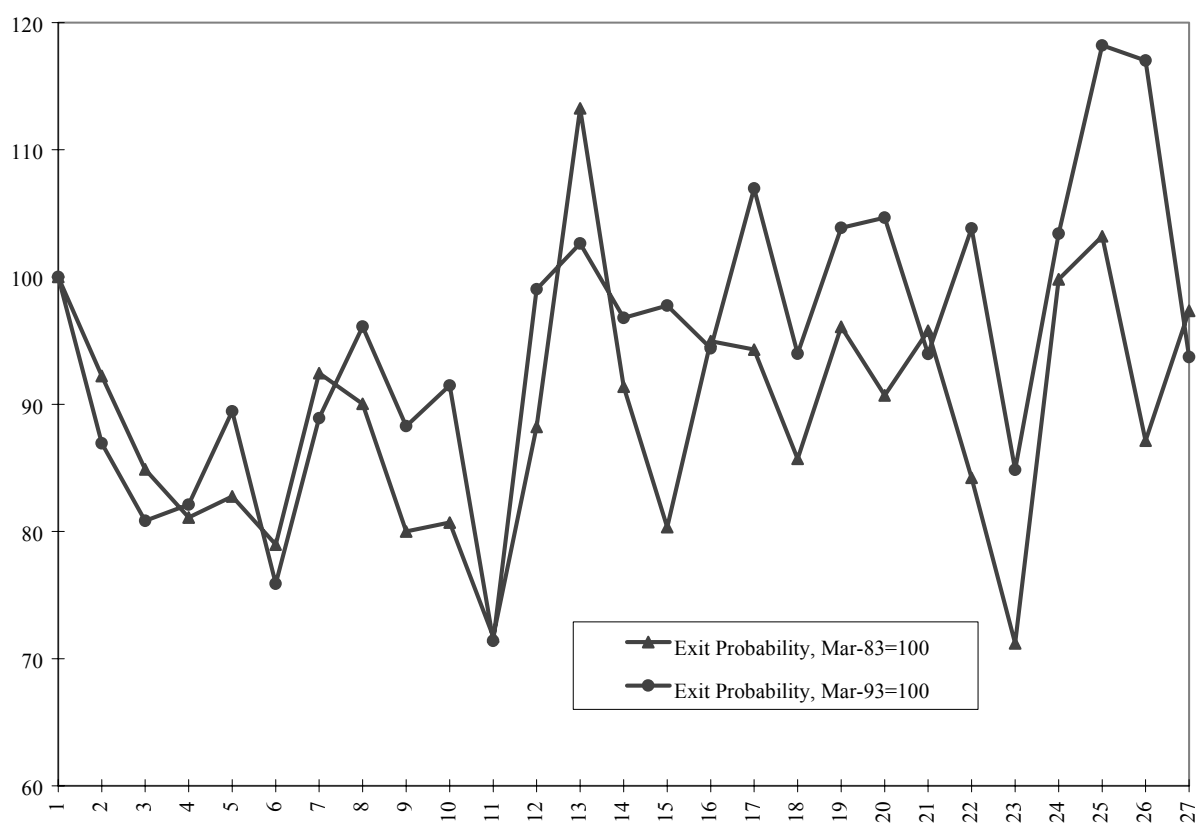

Source: ABS (unpublished).

If we turn to unemployment rates, see Figures 6 and 7, we see that the picture is similar: male unemployment rates are relatively lower in this cycle than in the 
previous one, while female unemployment rates are worse initially in coming out of this recession compared to the last but improve slightly later on, perhaps just as Working Nation programs were coming into play.

If we now turn our attention to the target group for the job compact, namely the unemployed with duration of 18 months or more, we see that as a proportion of the total unemployment (PLTU-WN) it has fallen very significantly since the introduction of Working Nation, see Figures 8 and 9. If we compare this variable over the two cycles it is clear that males in this group has fared better in coming out of this recession compared to the early eighties recession. The females in this target group have not fared any better or worse over the two cycles. The picture is very similar when we look at the Working Nation target group as a proportion of the long term unemployed with duration of 12 months or more, see Figures 10 and 11. Again, males have done much better in the recent recession than in the eighties recession.

If we look at the gross flows data and calculate the exit probabilities from unemployment into employment there is no obvious increase in exit probabilities, see Figure 12. A comparison over the two cycles is also not very helpful, see Figure 13. The monthly data are too noisy. However, Leeves (1997) in a paper using gross flows data finds a significant impact of labour market programs on exit probabilities.

\section{Forecasting long term unemployment (duration 18 months or more)}

One method of studying the impact of Working Nation on long term unemployment would be to estimate a structural model. Such models usually have as independent variable the duration of eligibility for unemployment benefits, a measure of "insider" power (eg union membership), and an index of wage flexibility, and a measure of labour market programs. In such a model the way to test for the impact of labour market programs would be to see the extent to which (say) the expenditure on labour market programs affects LTU9 . However, it is important to note that expenditure on labour market programs (or numbers of people on labour market programs) is endogenous: when unemployment and LTU is high expenditure (and numbers of people) on labour market programs increase endogenously. Such a model for a single country is difficult to estimate since most of the variables listed above have not changed at all, for example duration of unemployment benefit eligibility. Such models have been estimated for a cross-section of OECD countries with mixed success, see Junankar and Pehkonen. (1996).

As an alternative, we have followed the approach from some previous empirical work by Chapman, Junankar and Kapuscinski (1992) which successfully utilised simple reduced form time-series models linking the proportion of long term unemployment (LTU, defined as people continuously unemployed for 52 weeks and over) with the unemployment rate and the

\footnotetext{
9 Data on Australian labour market programs is available on a quarterly basis only from 1989. This does not give us a sufficient basis for estimating econometric models even if we ignore the issue of endogeneity of this variable, which could have been allowed for by using instrumental variable estimation.
} 
past history of long-term unemployment to forecast the behaviour of LTU. Since the emphasis of the Working Nation was a slightly different target group of people from the usual LTU (duration of 52 weeks or more) to those continuously unemployed for 18 months and over (LTU-WN), it seems appropriate to modify these forecasting models to fit this target population.

If we look at Diagram 1, it is easy to see that in a recession the inflows into unemployment would increase and the outflows decrease. The inflows into unemployment come in with zero durations while the outflows are typically with shorter durations of unemployment. As a result, in the first instance, the proportion of long term unemployment falls, and then after a period of time begins to rise. Hence the proportion of long term unemployment depends on lagged unemployment rates. This can also be seen from the actual data on unemployment and long term unemployment (Figures 1 and 2) which show that the peaks in LTU lag behind the increases in unemployment rates.

Given earlier work on adapting these models to the very long term unemployment (VLTU, or people unemployed for two years or more) (see Junankar and Kapuscinski (1993)), the similarity of time series behaviour of all three series dictated similar functional form and initial model specification for the LTU-WN.

Table 1: Estimated models of the proportion of unemployment with duration of 18 months and over (LTU-WN).

\begin{tabular}{|c|c|c|c|c|c|c|}
\hline & \multicolumn{2}{|c|}{ males } & \multicolumn{2}{c|}{ females } & \multicolumn{2}{c|}{ persons } \\
& beta & t-ratio & beta & t-ratio & beta & t-ratio \\
\hline pltu(-1) & 0.625 & 3.97 & 0.706 & 8.47 & 0.533 & 3.90 \\
\hline $\operatorname{pltu}(-2)$ & 0.235 & 1.40 & & & 0.200 & 1.67 \\
\hline pltu(-3) & -0.183 & -1.38 & & & & \\
\hline $\operatorname{ur}(-1)$ & -0.515 & -0.88 & 0.676 & 1.87 & -0.304 & -0.81 \\
\hline $\operatorname{ur}(-2)$ & 0.137 & 0.14 & 0.270 & 0.64 & 1.156 & 2.66 \\
\hline $\operatorname{ur}(-3)$ & 1.583 & 1.63 & & & & \\
\hline $\operatorname{ur}(-4)$ & -0.786 & -0.79 & & & & \\
\hline $\operatorname{ur}(-5)$ & -0.382 & -0.33 & & & & \\
\hline $\operatorname{ur}(-6)$ & 0.814 & 1.22 & & & & \\
\hline D4ue & -0.556 & -0.67 & -0.147 & -0.21 & -0.828 & -1.51 \\
\hline $\mathrm{q} 1$ & 0.163 & 0.09 & -1.985 & -2.64 & -1.562 & -2.63 \\
\hline $\mathrm{q} 2$ & 3.733 & 2.41 & 0.081 & 0.07 & 1.555 & 1.96 \\
\hline $\mathrm{q} 3$ & 2.221 & 1.24 & 0.056 & 0.08 & -0.392 & -0.65 \\
\hline constant & -0.874 & -0.64 & -3.485 & -2.50 & -1.563 & -1.94 \\
\hline
\end{tabular}

The final models chosen for the forecasting work are given in Table 1 with the basic diagnostics statistics presented in Table 2. In summary, these models fit the data accurately with no evidence of model misspecification or residual autocorrelation and for each specification the standard error of the estimated regressions is much smaller than the 
variability of the dependent variable. The data were consistent with standard prerequisites for cointegration (same order of stationarity of all the regressors). ${ }^{10}$

Table 2: Summary diagnostics of the estimated models (LTU-WN).

\begin{tabular}{|c|c|c|c|}
\hline & males & females & persons \\
\hline R2-adj & 0.93 & 0.86 & 0.94 \\
\hline SEE & 1.37 & 1.22 & 1.01 \\
\hline Std.dev.(y) & 5.31 & 3.34 & 4.24 \\
\hline DW & 1.97 & 2.41 & 2.12 \\
\hline ACF: lag 1 & -0.17 & -1.55 & -0.54 \\
\hline ACF: lag 2 & 0.59 & 0.92 & 0.51 \\
\hline ACF: lag 3 & -0.55 & 1.17 & -1.16 \\
\hline ACF: lag 4 & -0.77 & -1.21 & -1.71 \\
\hline Reset (2) & 3.42 & 7.67 & 0.97 \\
\hline
\end{tabular}

An interesting issue surrounding these models is their stability over the period when the Working Nation programs were implemented. We have carried out two tests to evaluate the robustness of our models in the period 1994.2 to 1996.4. Thus the Chow test is simply for a possible break in the structure at the second quarter of 1994. As the results in Table 3 reveal, there is no evidence of such instability. The Salkever test, on the other hand, tests the significance of prediction errors of our models in the post 1994.2 period. Again, the results suggest no evidence of structural problems at the 5\% significance level for all equations. Overall, therefore, these models can be described as capturing the essential elements of the behaviour of LTU-WN up to the end of the available data, i.e. 1996.4 and can be used as predicting models.

\section{Figure 14}

\section{Males: LTU is 18 months \& over}

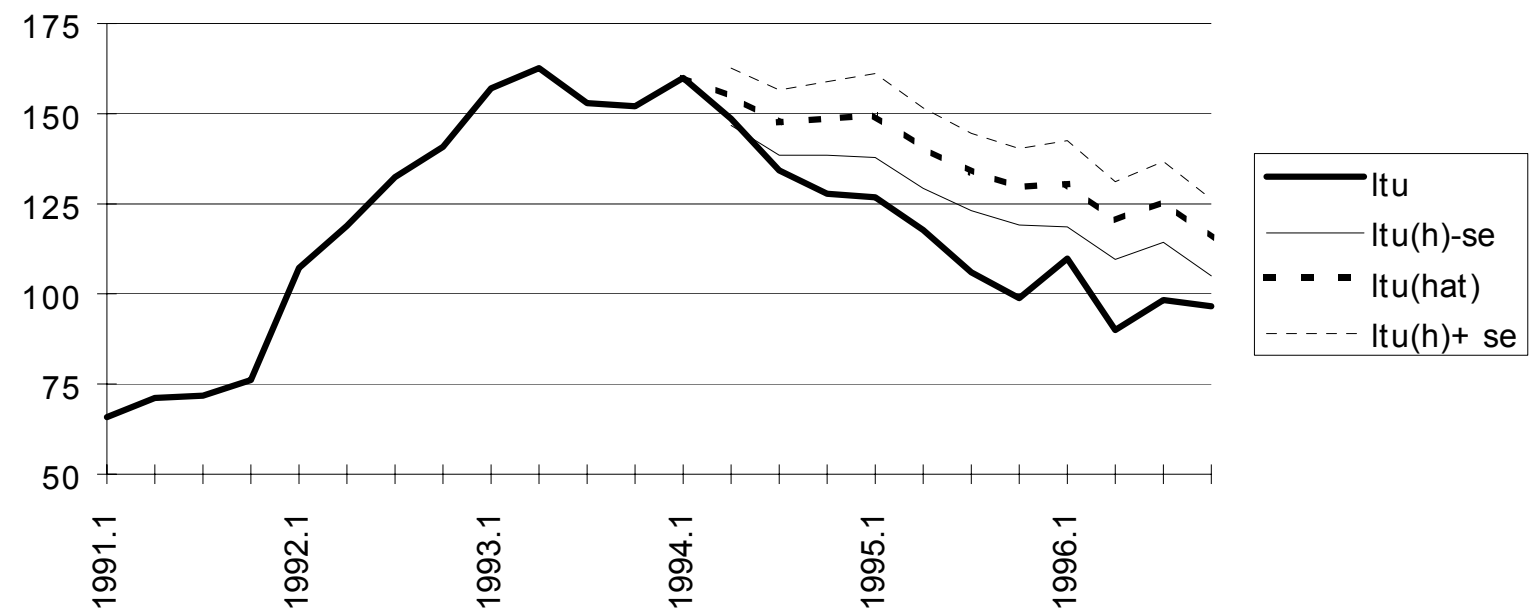

${ }^{10}$ In an earlier paper Chapman, Junankar and Kapuscinski (1992) found that the model supported a cointegrating relationship between the relevant variables. Also see EPAC (1996) Appendix 4. 
Figure 15

Females: LTU is 18 months \& over

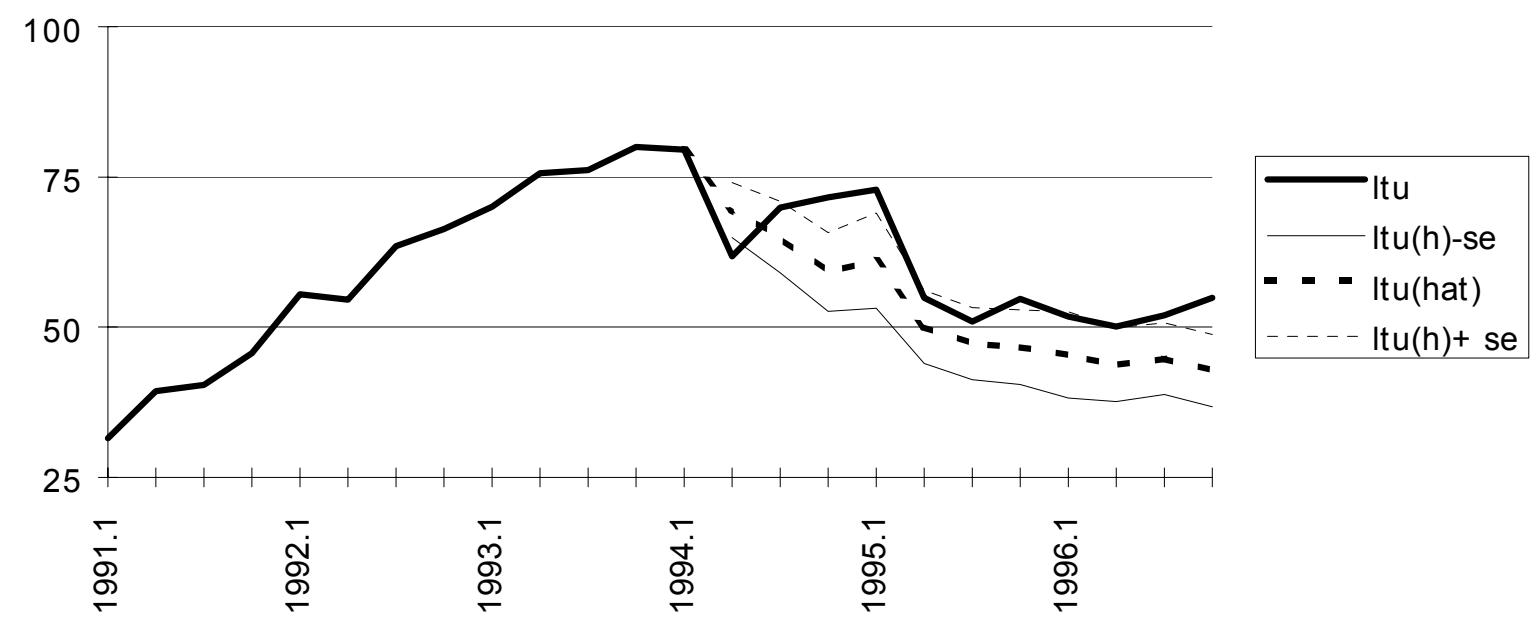

Figure 16 


\section{Persons: LTU is 18 months \& over}

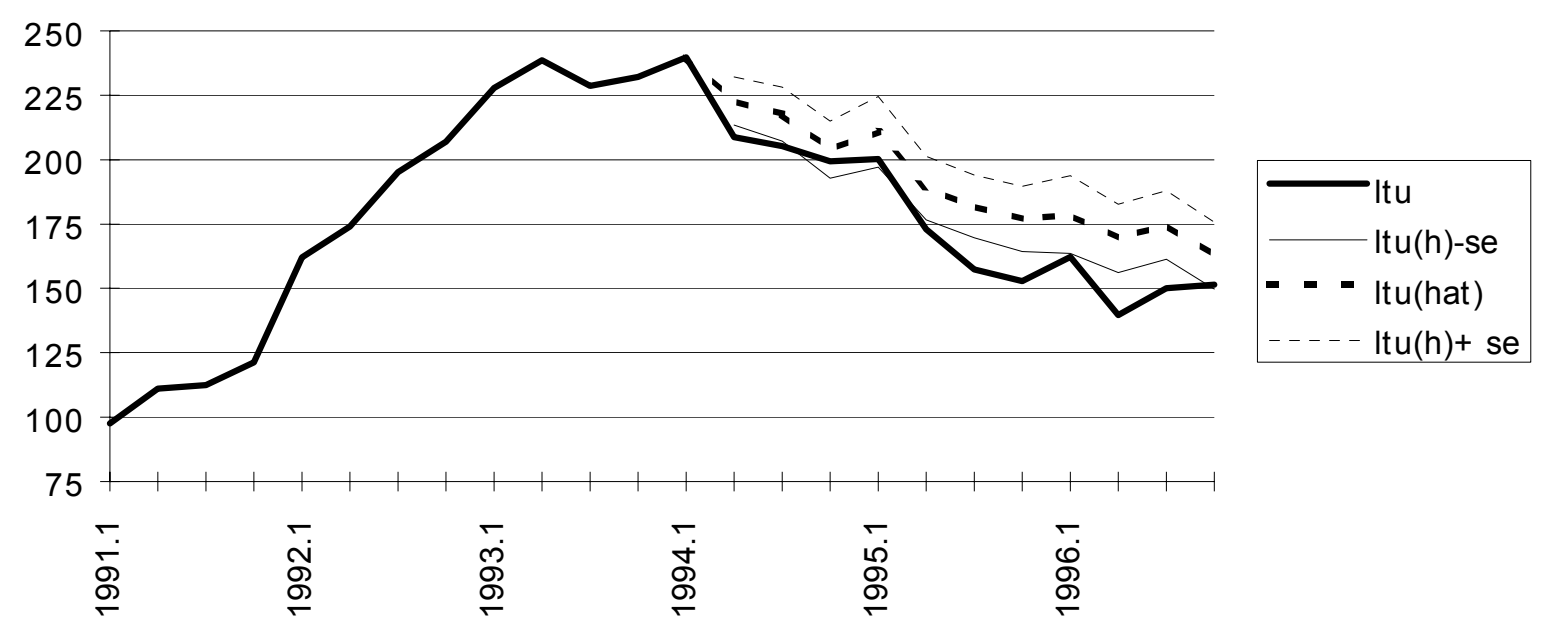

Table 3: Structural stability of the models during the operation of the Working Nation: 1994.2 - 1996.4.

\begin{tabular}{|c|c|c|c|}
\hline & males & females & persons \\
\hline Chow test & 0.118 & 0.119 & 0.106 \\
\hline Salkever test & 1.248 & 1.264 & 1.124 \\
\hline
\end{tabular}

Table 4: Prediction accuracy

\begin{tabular}{|l|r|r|r|}
\hline & \multicolumn{3}{|l|}{ LTU 18 months \& over } \\
& males & females & persons \\
\hline RMSE & 0.5237 & 0.1389 & 0.6746 \\
\hline Theil's U & 0.00453 & 0.00234 & 0.00386 \\
\hline
\end{tabular}

To evaluate the behaviour of LTU-WN under the Working Nation we have decided to utilise these models to project the expected outcomes of LTU-WN given the actual levels of unemployment rate in the 1994.2 - 1996.4 period. Such a procedure, under the assumption that the models capture the essential profile of LTU-WN, can be used to provide indirect evidence about the success of programs which remove unemployed from the stock of LTUWN. We should stress, however, that since other policies can also result in the reduction of this portion of the stock of unemployment (such as short-term (re-)training followed by a return to unemployment) this evaluation cannot be used as an unambiguous test of the effectiveness of the labour market programs of the Working Nation.

The main results of our experiments are presented in Figures 13,14 and 15. These figures compare the projections of long term unemployment with duration of 18 months and over (LTU-WN) conditional on the actual unemployment rates for males, females and persons with the actual profile of LTU-WN over the post-1994.2 period. (Note that these projections are based on dynamic forecasts, that is we use the predicted values of the dependent variable as the subsequent lagged dependent value.) For "readability" we have smoothed both series and also provided two standard error bounds on the forecasts of LTU-WN (which, statistically speaking, are equivalent to a $95 \%$ confidence interval). 
While our forecasts of LTU-WN are simulating the behaviour of long term unemployment on the basis of the pre-Working Nation structure of the labour market, the availability of data on commencements of labour market programs allows us to assess these forecasts from the perspective of Working Nation outcomes. Thus, figure xxx presents the ratio of exits from long term unemployment to total unemployment ${ }^{11}$. As forecast by our models, the data unambiguously provide the evidence that the Working Nation program has had a significantly more successful impact on males than on females. In addition, the actual outcomes also indicate that during the life of the Working Nation program the gap between outcomes for males and females was consistently of the same order of magnitude.

\section{Figure 17}

Exits from LTU to Labour market programs relative to total UE

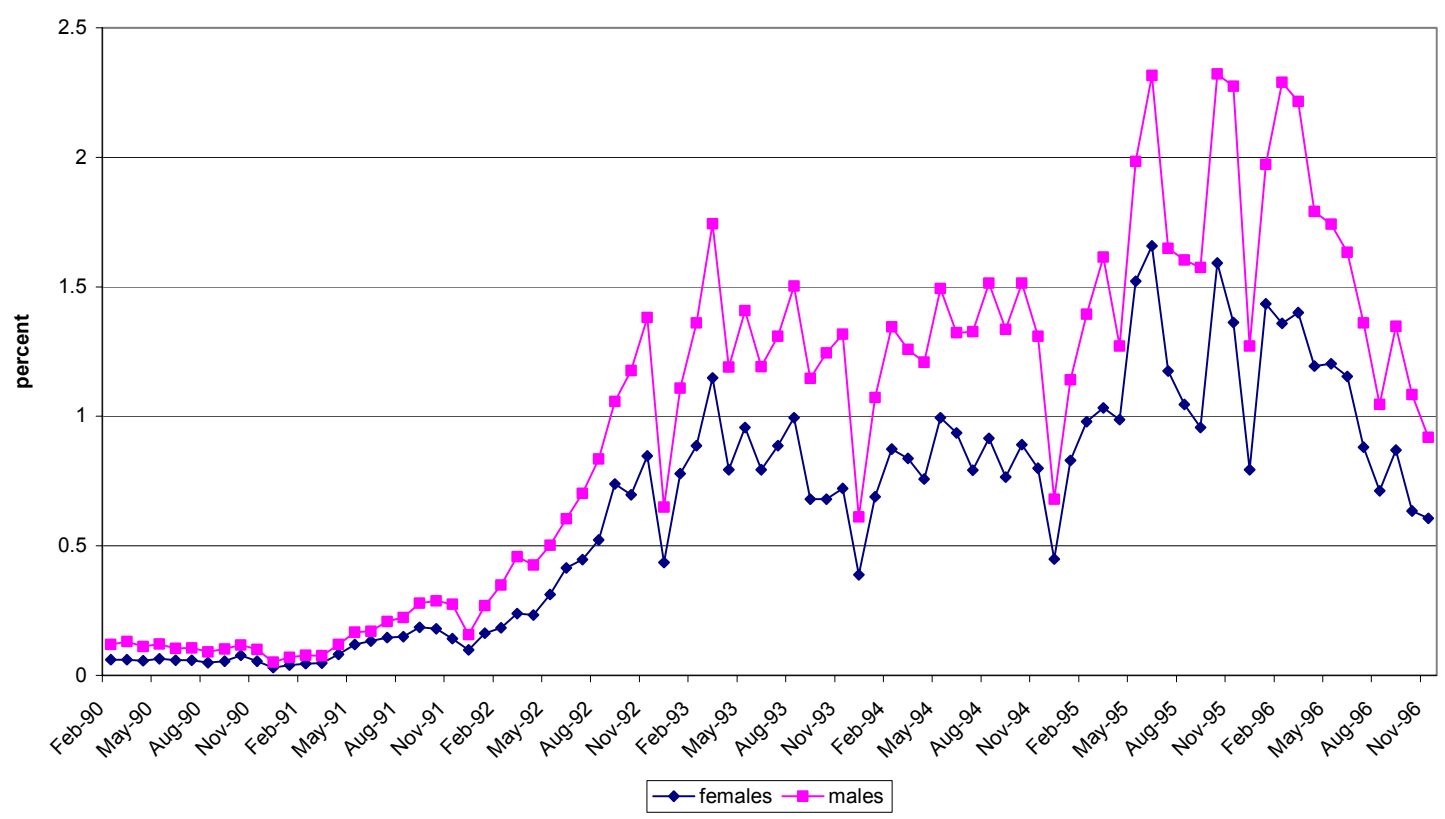

Source: Department of Employment, Education, Training and Youth Affairs, unpublished data.

The major points from these experiments are as follows:

- there appears to be a statistically significant effect from the Working Nation programs on males and females;

- the effects, however, are in the opposite direction - males appear to be benefiting from the programs, while females appear to be adversely affected;

- $\quad$ as a result the net effect (i.e. for persons) is positive but very weakly significant;

- these effects appear to be of constant magnitude almost to the end of the forecast period.

\section{Estimating Employment Functions}

\footnotetext{
${ }^{11}$ Due to differences in the definitions of long term unemployment used by DEETYA (which is based on the CES definition) and ABS, we have used the gender-specific total number of unemployed as the deflator.
} 
An even stronger test of the effectiveness of labour market programs is to see to what extent the programs increased net employment. Although it is true that the general macroeconomic stance of government policy is crucial to whether there would be an increase in net employment, the aim of labour market programs is to facilitate an increase in employment given the macroeconomic stance of the government. We would argue that the success of labour market programs depends on the government having monetary and fiscal policies that are expansionary at the same time that it is increasing expenditure on labour market programs.

As we see it, the aim of wage subsidy programs is to increase the quantity of labour demanded, and assuming a regime of minimum wages (as we have in Australia) this should lead to an increase in employment ${ }^{12}$. Another way of looking at labour market programs is to think of them as increasing the supply of skilled labour, which ceteris paribus, should increase their employment. As long as their is no substitution, deadweight loss, or displacement, this should also lead to an increase in net employment.

In an attempt to study the macroeconomic impact of Working Nation on the labour market, we estimated a simple employment function, see Russell and Tease (1991) and OECD (1993), using as the dependent variable the employment of wage and salary earners. As independent variables we used lagged real unit labour costs, lagged real GDP, and lagged values of the dependent variable. As the expenditure on labour market programs (or the number of people on these programs) is endogenous we have not used this variable, unlike OECD (1993). Clearly, when unemployment rises the government spends more on labour market programs and more people are on various programs and hence we would expect that employment and the variable labour market programs would be negatively correlated. Since Working Nation was such a major shift in government policy what we have done is to estimate our model upto the introduction of Working Nation and then compared the forecasts with the actual data outside the sample period.

Instead of using total employment we decided to use wage and salary earners employment as this variable would be most affected by the labour market programs under Working Nation, with the exception of the NEIS programs. Clearly, self employment would be less likely to be affected by labour market programs. We estimated employment functions for males and females separately using real unit labour costs and lagged GDP as independent variables. To allow for lagged adjustment of employment to changes in the independent variables we introduced lagged dependent variables. Having carried out preliminary tests for cointegration we found that the variables were all I(1) and were cointegrated, see Tables 5 and 6 . Using our estimates for employment function on data upto the introduction of Working Nation (second quarter 1993) we then dynamically forecast employment

12 Michael Keating in a letter to us comments that the main purpose of wage subsidy programs is not to increase labour demand but to increase the employability of the long term unemployed. General macroeconomic policy, he argues, sets the scene for increasing employment. 
outside the sample period to see if Working Nation had made a significant difference to employment in aggregate.

Table 5: Unit root tests

\begin{tabular}{|l|c|c|}
\hline Variable & DF test & No. of lags \\
\hline lwsem & -3.44 & 4 \\
\hline lswef & -2.42 & 4 \\
\hline lgdp & -1.75 & 2 \\
\hline lulc & -1.76 & 4 \\
\hline
\end{tabular}

Note: The critical value at $10 \%$ level is -3.13 .

Table 6: Cointegration tests:

\begin{tabular}{|l|c|c|}
\hline & DF test & No. of lags \\
\hline Males & -2.83 & 4 \\
\hline Females & -1.77 & 4 \\
\hline
\end{tabular}

Note: The critical value at $10 \%$ level is -3.45 .

The estimated employment function is presented in Table $7^{13}$.

Table 7: Employment functions, males and females

(dependent variable is employed wage and salary earners)

\begin{tabular}{|c|c|c|c|c|}
\hline \multirow[t]{2}{*}{ Regressor } & \multirow{2}{*}{$\begin{array}{c}\text { Males } \\
\text { Coefficient }\end{array}$} & \multirow{2}{*}{ T-ratio } & \multicolumn{2}{|c|}{ Females } \\
\hline & & & Coefficient & T-ratio \\
\hline lwsem(-1) & 0.928 & 17.96 & & \\
\hline lwsef(-1) & & & 0.887 & 8.98 \\
\hline $\operatorname{lgdp}(-1)$ & 0.257 & 4.01 & 0.268 & 3.07 \\
\hline $\operatorname{lulc}(-1)$ & -0.165 & -4.44 & -0.116 & -2.09 \\
\hline $\mathrm{q} 1$ & -0.014 & -3.71 & -0.028 & -6.55 \\
\hline $\mathrm{q} 2$ & -0.005 & -1.25 & 0.004 & 0.90 \\
\hline $\mathrm{q} 3$ & -0.031 & -7.61 & -0.028 & -6.23 \\
\hline \multirow[t]{2}{*}{ constant } & -1.739 & 2.70 & -1.728 & -2.58 \\
\hline & \multicolumn{4}{|c|}{ Diagnostics } \\
\hline R-barsq & 0.941 & & 0.984 & \\
\hline $\mathrm{DW}$ & 2.446 & & 2.458 & \\
\hline ACF-lag 1 & -1.39 & & -1.35 & \\
\hline ACF-lag 2 & 0.71 & & 1.61 & \\
\hline ACF-lag 3 & -0.88 & & -1.01 & \\
\hline ACF-lag 4 & -0.70 & & -0.38 & \\
\hline RESET(2) & 0.011 & & 3.411 & \\
\hline
\end{tabular}

Table 8: Prediction evaluation

13 See Appendix A for estimates using an error correction model. 


\begin{tabular}{|l|r|r|}
\hline & \multicolumn{1}{|c|}{ males } & \multicolumn{1}{|c|}{ females } \\
\hline RMSE & 0.0506 & 0.0475 \\
\hline Theil's U & 3.703 & 2.272 \\
\hline
\end{tabular}

As there has been substantial movement in increasing labour productivity since the mideighties, we have also conducted CUSUM-square tests of the stability of the estimated employment functions. The results of these tests indicate that, past the initialization of the recursive estimates, the estimated regression do not suffer from structural breaks. This outcome can be taken as evidence that the gains in labour productivity have not been obtained siginificantly at the expense of employment levels.

In general the employment functions fit the data well and there appear to be no statistical problems with the estimates. However, forecasts of wage and salary employment consistently overestimate the actual series suggesting that either there was a structural break or that the model is not capturing some essential features of the employment relationship. On face value these estimates would suggest that the labour market programs were not successful in increasing net employment even if they were successful in decreasing unemployment and long term unemployment (see Figures 16 and 17). It is possible that the tight fiscal stance that the government took in the 1995-96 budget led employers to be circumspect about employing new workers. This issue needs further investigation.

\section{Figure 18}

\section{Wage and salary eamers: males}

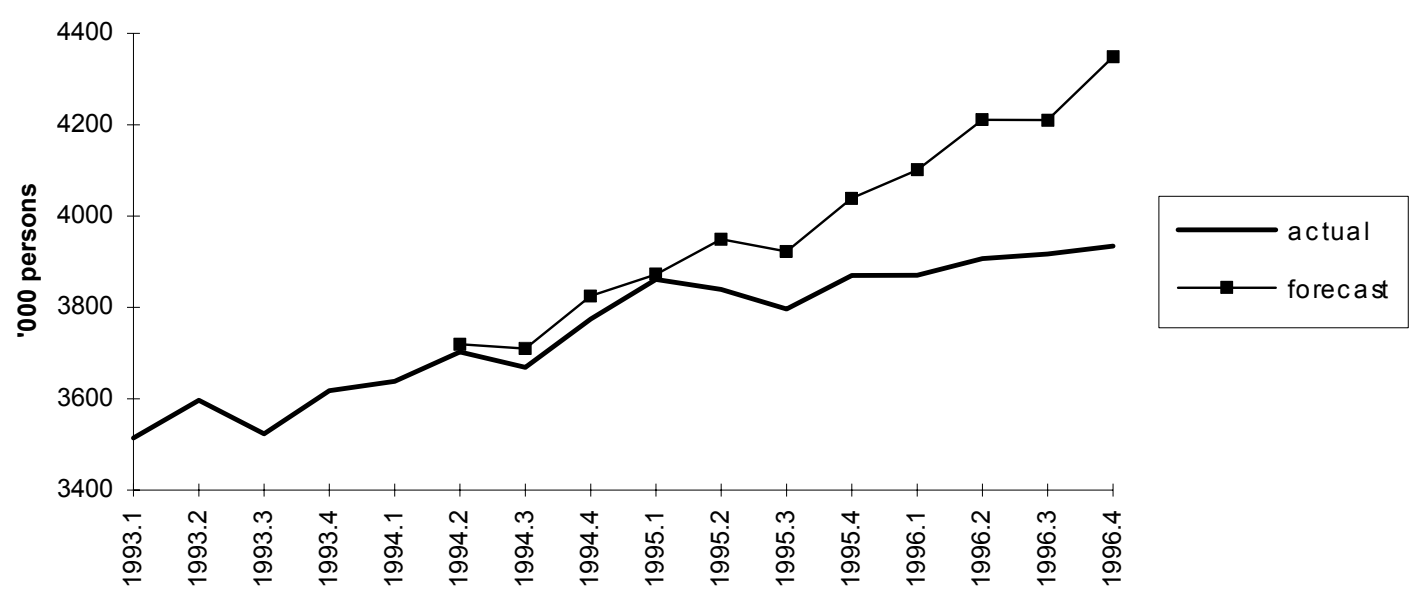

Figure 19 


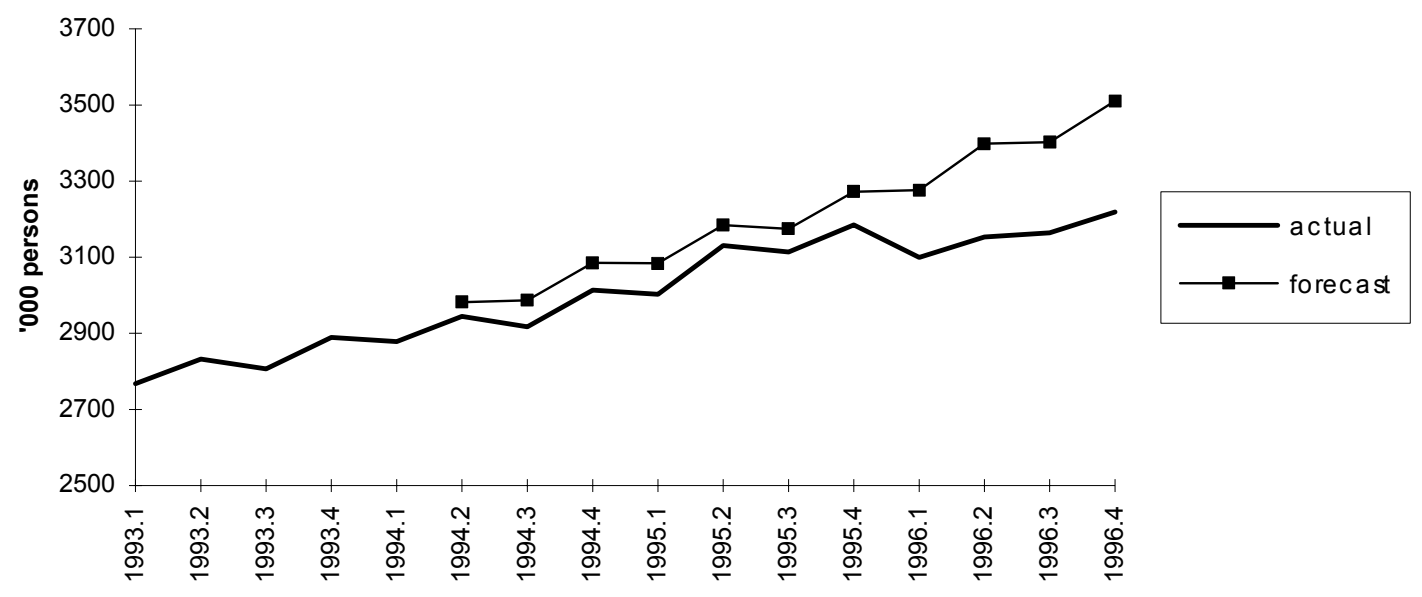

\section{Conclusions}

Our general conclusion is that labour market programs under Working Nation seem to have had some effect on lowering unemployment and long term unemployment for males and persons, but the results for females is ambiguous. Soon after the introduction of Working Nation in the 1995-96 budget the government introduced tight fiscal policies to curtail the budget deficit and decreased expenditures on labour market programs. However, with the new Coalition government the programs were aborted after a very short time and some of the programs had a very short life span and no final judgement can be made on the success or otherwise of Working Nation. It is a truism to state that LMPs need to continue for some time there is no quick fix available. We would argue that for the labour market programs to be really successful we should have supportive macroeconomic policies to increase the demand for labour.

Our analysis emphasises the importance of disaggregation by gender: because the programs were targeted at LTU, and women typically do not receive benefits so do not have an incentive to register with CES. Hence the Working Nation programs were likely to be offered mainly to males, rather than females. Any future labour market programs that target the long term unemployed have to be aware that under the usual indicators like duration of receiving unemployment benefits, or attendance at CES offices is likely to miss out long term unemployed females.

Although our analysis has focussed on macro effects, it is important to note that we cannot infer macroeconomic effects from micro studies because of the problems of substitution, displacement, or deadweight loss. Further research is also needed on microeconomic data, especially the longitudinal study, the Survey of Employed and Unemployed Persons (SEUP). 
To conclude, our results suggest that although Working Nation had a very short life it succeeded in helping the long term unemployed: it was a very valuable social experiment which was unfortunately aborted for political reasons. 


\section{References}

Blanchard, O. and L. Summers (1986) Hysteresis and the European Unemployment Problem, in S. Fischer (ed.) NBER Macroeconomics Annual 1986.

Burgess, J. (1995) “A Note on the Post-White Paper Interpretation of Labour Force Data", Australian Bulletin of Labour, 21 (1), 71-75.

Calmfors, L. (1994) "Active Labour Market Policy and Unemployment- A Framework for the Analysis of Crucial Design Features", OECD Economic Studies, 22, Spring 1994, 7-47.

Chapman, B.J., P.N. Junankar \& C.A. Kapuscinski (1992), 'Projections of Long Term Unemployment', Australian Bulletin of Labour, Vol. 18, pp.195-207.

Commission of the European Communities (1993) Growth, Competitiveness, and Employment: The Challenges and Ways Forward into the 21st Century (White Paper), Luxembourg: Office for the Official Publications of the European Communities.

Commonwealth of Australia (1994), Working Nation: Policies and Programs, Canberra: AGPS.

Connolly, G. and D. Nicol (1997) "The Effect of Expenditure on Labour Market Assistance and Urban and Regional Development on the Incidence of Longterm Unemployment", paper presented to the Australian Labour Market Research Conference, Fremantle, 13-14 February, 1997.

Crean, Simon (1995) Working Nation: The First Year, 1994-95, DEET, Canberra.

DEETYA (1996) Working Nation: Evaluation of the employment and education and training elements, Evaluation and Monitoring Branch, Economic and Policy Analysis Division, DEETYA, Canberra.

DEETYA (1997) The Net Impact of Labour Market Programmes: Improvements in the Employment Prospects of those Assisted, Evaluation and Monitoring Branch, Economic and Policy Analysis Division, EMB Report 2/97, DEETYA, Canberra.

Dolton, P. and D. O'Neill (1996) 'The Restart effect and the return to full-time stable employment', Journal of the Royal Statistical Society, Series A, 159, Part 2, 275288.

EPAC (1992), Unemployment in Australia, Council Paper No. 51, Canberra, AGPS.

EPAC (1996) Future Labour Market Issues for Australia, Commission Paper No. 12, Canberra, AGPS. 
Jarvie, W. and R. Mckay (1993), "Perspectives on DEET Labour Market Programs", and Comment by P.N. Junankar, Centre for Economic Policy Research, ANU, Discussion Paper No.296.

Junankar, P.N. (1988), Very Long Term Unemployment, Commission of the European Communities, Luxembourg.

Junankar, P.N. \& C.A. Kapuscinski (1990), 'The Duration of Unemployment in Australia: Memory and Measurement', Centre for Economic Policy Research, ANU, Discussion Paper No. 238.

Junankar, P.N. and J. Pehkonen (1996) "Long-Term Unemployment in OECD Countries: do institutions matter", School of Business and Economics, University of Jyvaskyla, Working Paper No. 162/96.

Kenyon, P. et al (1993), "Policy Forum on Long Term Unemployment", Australian Economic Review, 2, 93, pp. 19-47.

Kenyon, P. (1994), "The Job Compact: What does the International Evidence on Active Labour Market Policies Suggest About the Likelihood of its Success", Australian Bulletin of Labour, 20 (4), 272-297.

Leeves, G. (1997) “Duration specific Unemployment Outflows and Labour Market Training", Australian Labour Market Research Workshop, Fremantle 13-14 February, 1997.

OECD (1993) "Active Labour Market Policies: Assessing Macroeconomic and Microeconomic Effects", Employment Outlook, OECD, Paris.

Piggott, J. and B. Chapman (1995) "Costing the Job Compact", Economic Record, 71, 313-28.

Russell, W. and W. Tease (1991), Employment, Output and Real Wages, Economic Record, 67 (196), 34-45. 


\section{Appendix A: Data and Sources}

All data are from the AUSTATS data base. The equivalent ABS publications are given in the following table.

\begin{tabular}{|l|l|l|}
\hline Variable & Definition & Source \\
\hline LMP & Labour Market Programs & DEETYA, unpublished. \\
\hline LTU-WN & $\begin{array}{l}\text { Long term unemployed/total } \\
\text { unemployed. }\end{array}$ & $\begin{array}{l}\text { ABS Labour Force } \\
\text { Survey, unpublished } \\
\text { and ABS 6203.0. }\end{array}$ \\
\hline $\begin{array}{l}\text { employment } \\
\text { demand }\end{array}$ & wage and salary earners & ABS 6248.0 \\
\hline labour costs & $\begin{array}{l}\text { unit labour costs (= total } \\
\text { wage bill/domestic product) }\end{array}$ & $\begin{array}{l}\text { ABS 6302.0 (for average } \\
\text { wages) } \\
\text { ABS 6203.0 (for total } \\
\text { employment) }\end{array}$ \\
\hline
\end{tabular}




\section{Appendix B: Estimates of Error Correction Models of the employment function}

Based on the stationarity properties of the variables used in the analysis in Section 9 it is also possible to estimate an Error Correction Model linking the employment variable with the cost variable (ULC) and the aggregate demand variable (GDP). Table below presents an unrestricted specification of an ECM model for males and females.

Table A1: Employment function: Error Correction Models

(dependent variable is change in employed wage and salary earners)

\begin{tabular}{|l|r|r|r|r|}
\hline Regressor & \multicolumn{2}{|c|}{ Males } & \multicolumn{2}{c|}{ Females } \\
\hline & Coefficient & T-ratio & Coefficient & T-ratio \\
\hline Dlwsem1 & -0.414 & -2.15 & & -1.80 \\
\hline Dlwsef1 & & & -0.362 & 1.06 \\
\hline Dlgdp1 & 0.786 & 2.15 & 0.453 & 0.61 \\
\hline Dlulc1 & 0.154 & 1.20 & 0.086 & -0.21 \\
\hline lwsem1 & -0.032 & -0.56 & -0.023 & 1.79 \\
\hline lgdp1 & 0.212 & 2.35 & 0.218 & -2.04 \\
\hline Lulc1 & -0.142 & -2.58 & -0.154 & -2.43 \\
\hline Q1 & -0.004 & -0.59 & -0.019 & 0.99 \\
\hline Q2 & 0.001 & 0.21 & 0.004 & -2.18 \\
\hline Q3 & -0.021 & -3.44 & -0.017 & -1.89 \\
\hline constant & -1.639 & -2.08 & -1.731 & 0.803 \\
\hline & & & & 1.958 \\
\hline R-sqr (adj) & & 0.794 & & 0.11 \\
\hline DW & & 2.185 & & -1.09 \\
\hline ACF-lag1 & & -0.59 & & -0.61 \\
\hline ACF-lag2 & & -0.96 & & 1.422 \\
\hline ACF-lag3 & & -0.65 & & \\
\hline ACF-lag4 & & -0.40 & & \\
\hline RESET(2) & & 2.762 & & \\
\hline & & & & \\
\hline
\end{tabular}

Given that not all the short-term dynamics terms in the ECM specifications are significant we have also tested a simplifying restriction on the above models with all the short-term dynamics variables excluded from the model. The results of these tests are given in Table A2. These results suggests the simpler form of the equation as given in Section 9 as the preferable specification for both males (at $10 \%$ significance level) and for females.

Table A2: Tests of restrictions on the estimated ECM

\begin{tabular}{|l|r|r|}
\hline & Males & Females \\
\hline F-test & 2.403 & 0.373 \\
\hline MSL & 0.093 & 0.773 \\
\hline
\end{tabular}




\section{Appendix C}

Wage and Salary Earners (Persons) in two cycles, 1983 and 1993

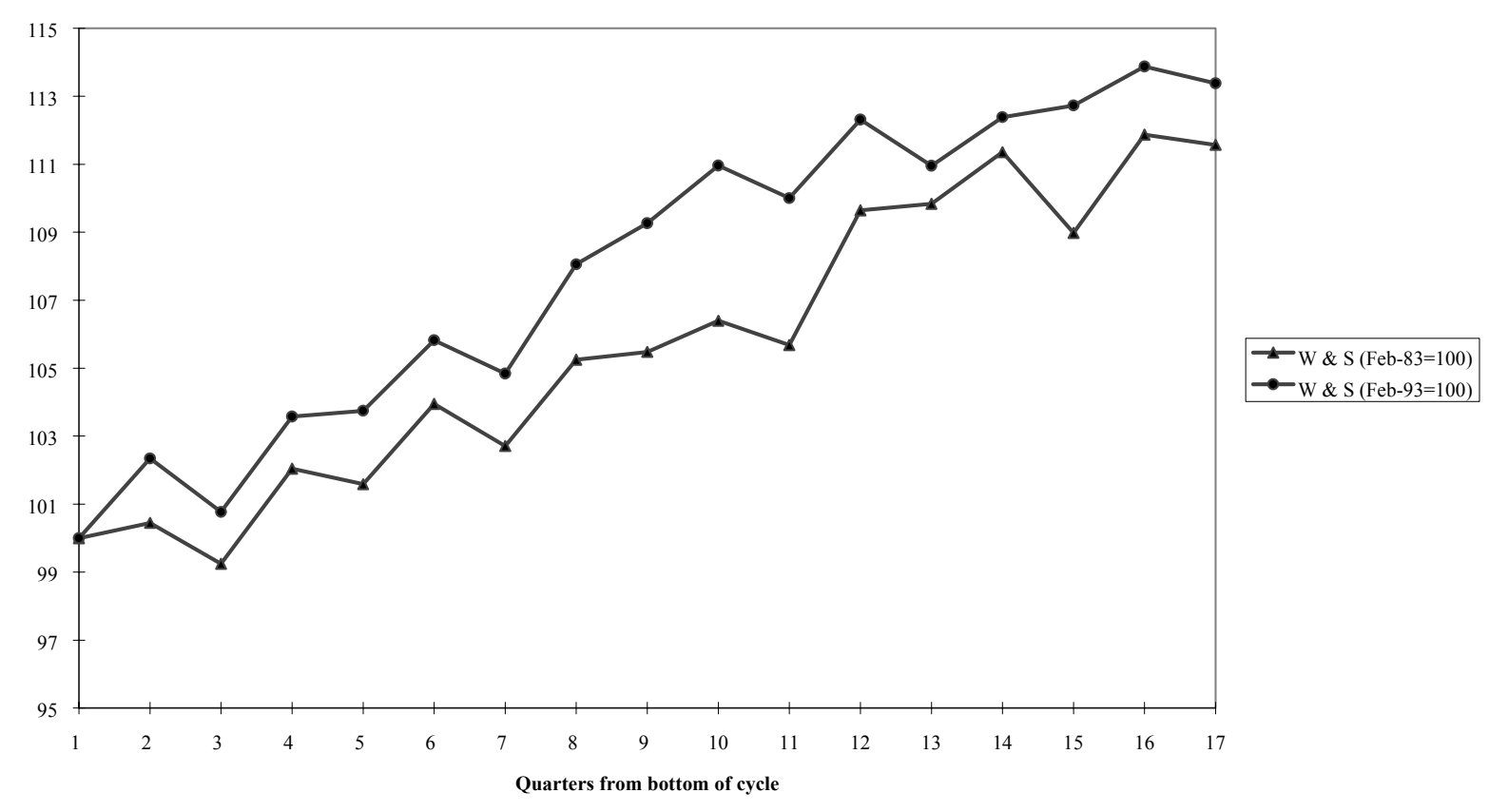

Source: ABS AUSSTATS. 
Was Working Nation Working?

A Failed Experiment or a Premature Abortion?

\author{
P.N. Junankar \\ and \\ Cezary A. Kapuscinski
}




\section{Was Working Nation Working? A}

Failed Experiment or a Premature

\section{Abortion?}

1. Introduction

With increase in unemployment $(\mathrm{U})$ and long term unemployment LTU):

Important new policy

-Working Nation (May 1994).

- New Coalition govt. in 1996 buried it!

Was Working Nation responsible for fall in $U$ and LTU?

Use simple econometrics on macro data to evaluate success of Working Nation.

Preview: a valuable social experiment aborted for political reasons! 
2. Trends in $U$ and
LTU

Big increase in $U$ and LTU after the recession.

See Figures 1 and 2.

U and LTU rise rapidly but fall slowly.

Note that U and LTU started falling by 1994. 
Figure 1: Unemployment Rates, Males and Females (seasonally adjusted)

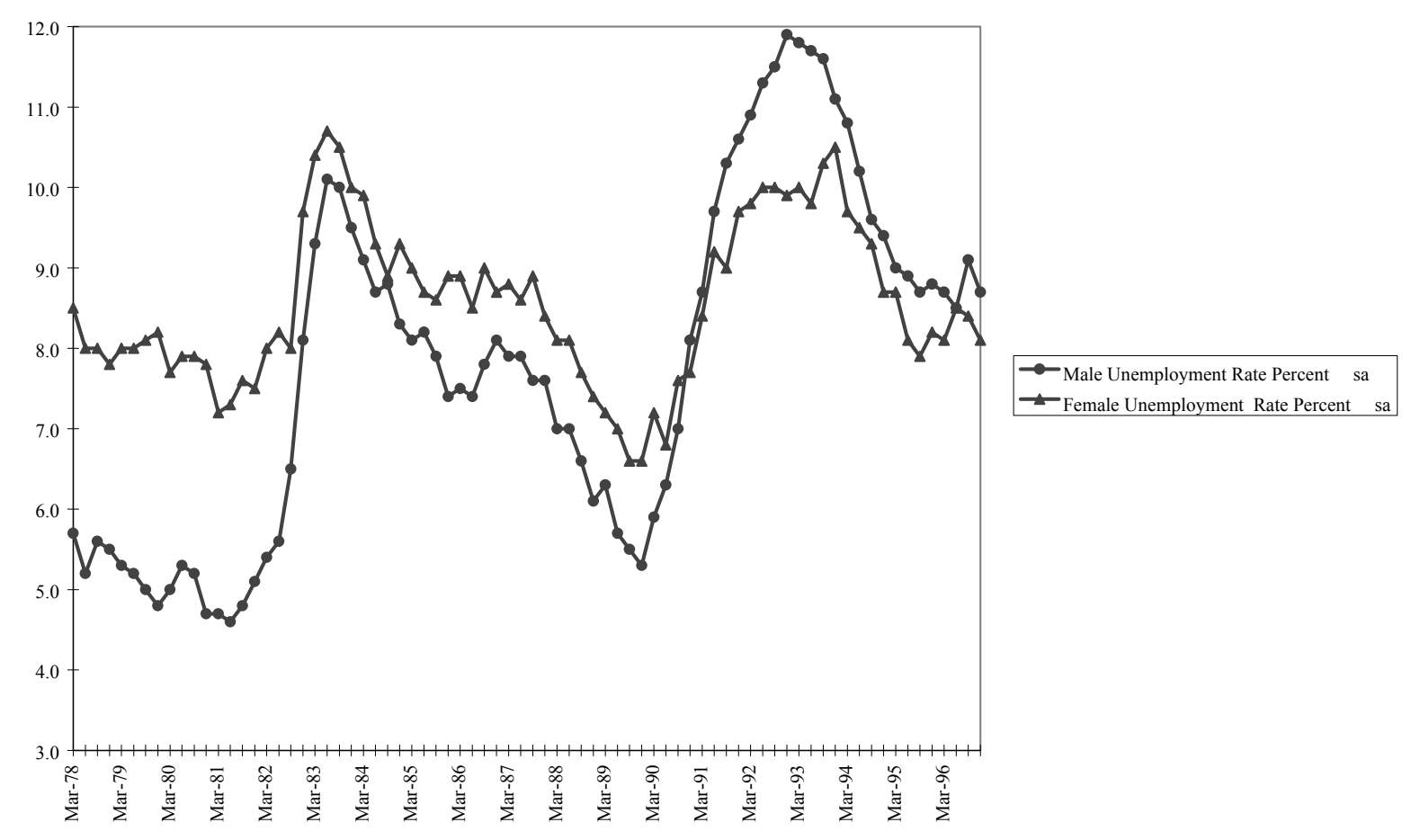

Source: ABS 6203

Figure 2: Long term unemployed: comparison of different durations: persons

Persons: LTU

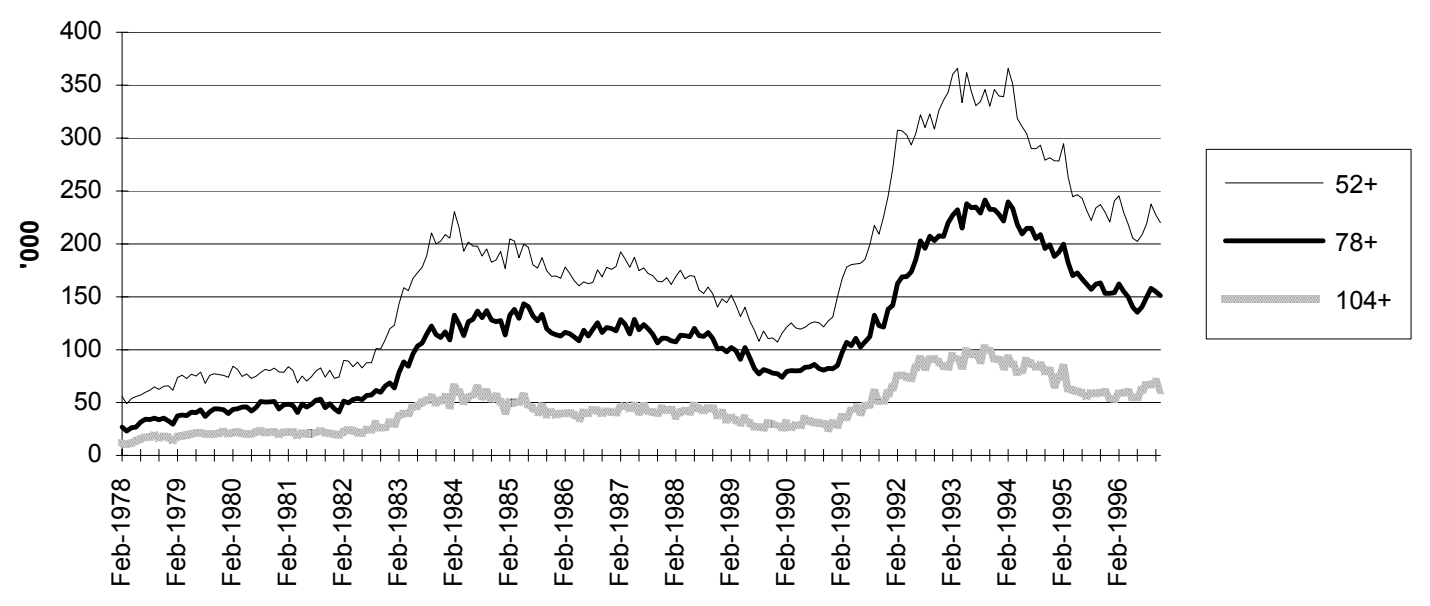

Source: ABS 6203 


\section{Working Nation: The Policy Package}

Emphasis on LTU and those likely to become LTU.

Public Policy Issues: Targeting of $U$ and LTU for efficiency, equity and social reasons. Hysteresis.

$\mathrm{U}$ and LTU has fallen significantly since 1994.

Main elements: Job Compact, YTI, etc. Focus on LTU.

Note reciprocal obligations and case management.

Policy innovation: Use of nongovernment agencies to deliver case management, monitored by ESRA. 
Question: To what extent is fall in $U$ and LTU due to policy?

Decrease in funding for Working Nation in Budget 1995-96.

Coalition Budget of 1996-97 killed Working Nation!

\begin{tabular}{l}
\hline $\begin{array}{l}\text { 4. Evaluating "success" of } \\
\text { policies }\end{array}$ \\
\hline
\end{tabular}

A conceptual framework:

Inflows and Outflows. Policies affect demand for labour (by wage subsidies),

supply of labour (by improving quality via training),

and working of labour market (by better information, via counselling etc). 


\section{Diagram 1: Labour Market Stocks and Flows}

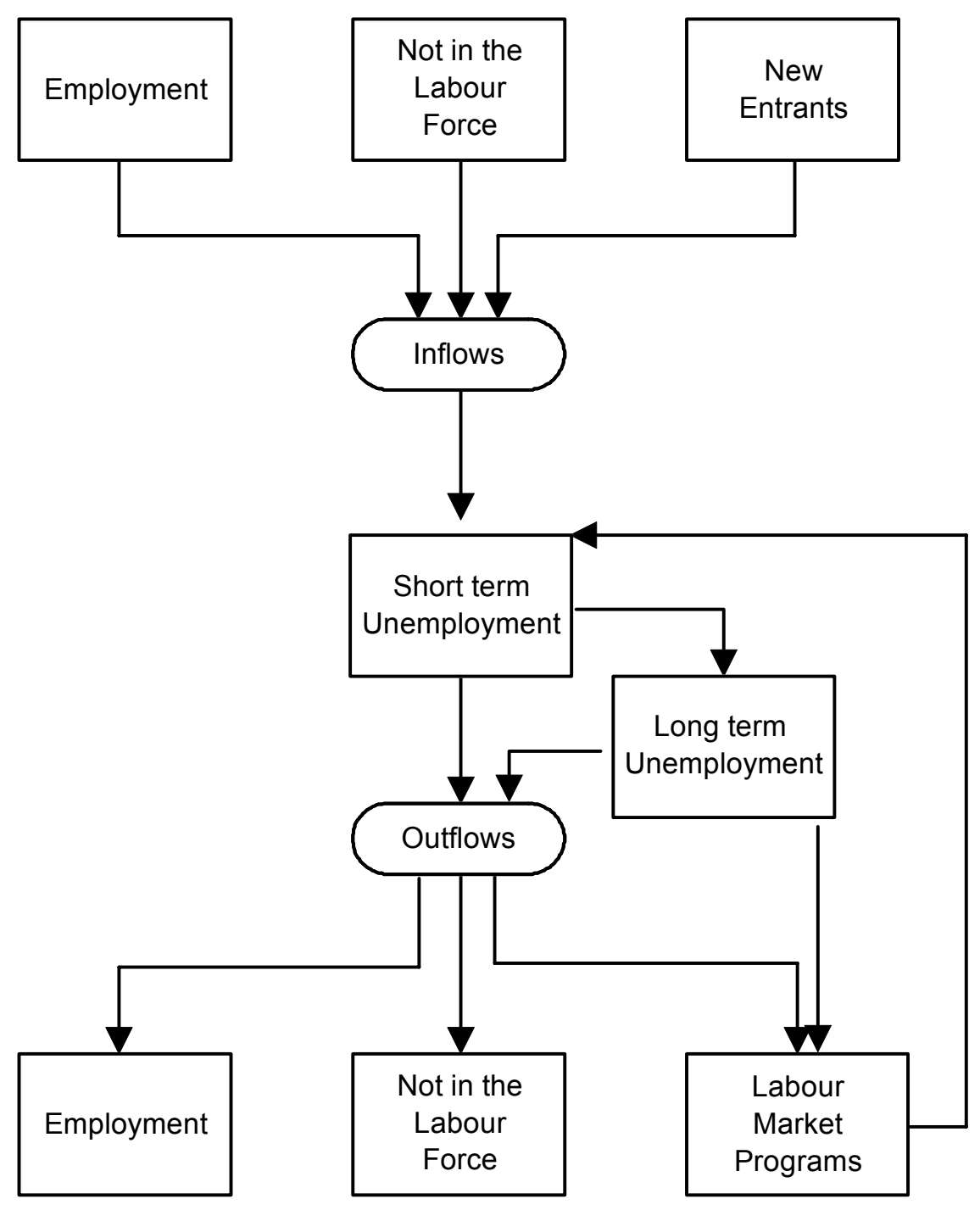




\section{Questions:}

(i) Have employment prospects improved for program participants?

(ii) Has U and LTU decreased by more than expected?

(iii) Has employment increased? 
Macro: What is the counter-factual?

What would $U$ and LTU have been in absence of Working Nation?

Growth in employment, decline in $U$ and LTU - is this success because of Working Nation?

Assessing Labour Market Programs

(a) elasticity of labour demand;

(b) deadweight loss

(c) substitution

(d) job displacement

(e) labour force participation;

(f) employers attitudes?

Screening

Micro: Matched samples, randomised trials, but "ethical problems". 
Econometric methods on longitudinal data, SEUP.

Problem of selection bias-"creaming".

We look at macro impact by:

(a) Comparing $U$ and LTU in two recessions.

(b) Estimate model for LTU and compare forecasts with actual data.

(c) Estimate employment functions, and compare forecasts with actual data.

5. ALP Govt. Evaluations

Crean's Report:

"Remarkable achievements";... "very strong employment growth, declining unemployment and falling long-term unemployment". 
Working Nation: marked fall in long term-unemployment-much better outcome than in the recovery of the mid1980s.

Fall for those unemployed 18 to 24 months, Job Compactees, has been even greater.

Evaluation studies show higher probabilities of employment for LMP participants - but problem of "creaming".

Need a proper control group.

Employers survey: Not willing to touch LTU. 
6. Coalition Government's Evaluation

The DEETYA (1996) and (DEETYA, 1997)

are circumspect about success of Working Nation.

Labour market programs increased probability of employment.

However, many of those on programs returned to unemployment.

More expensive to help the longer term unemployed.

Finds that wage subsidy programs (JobStart) was much more successful JobTrain or SkillShare. 


\section{Preliminary \\ Results}

Australian data: What is the counterfactual?

Male employment growth from 1993(1) is slightly better than 1983 recession, but female employment worse towards end.

Figures 3 and 4

Similarly, male unemployment better, female slightly worse.

Figures 5 and 6

LTU-WN (18+months) for males better now than eighties, for females mixed.

Figures 7 and 8. 
Figure 3: Male Employment Growth in two cycles, 1983 and 1993

Male Employment Growth in two cycles, 1983 and 1993

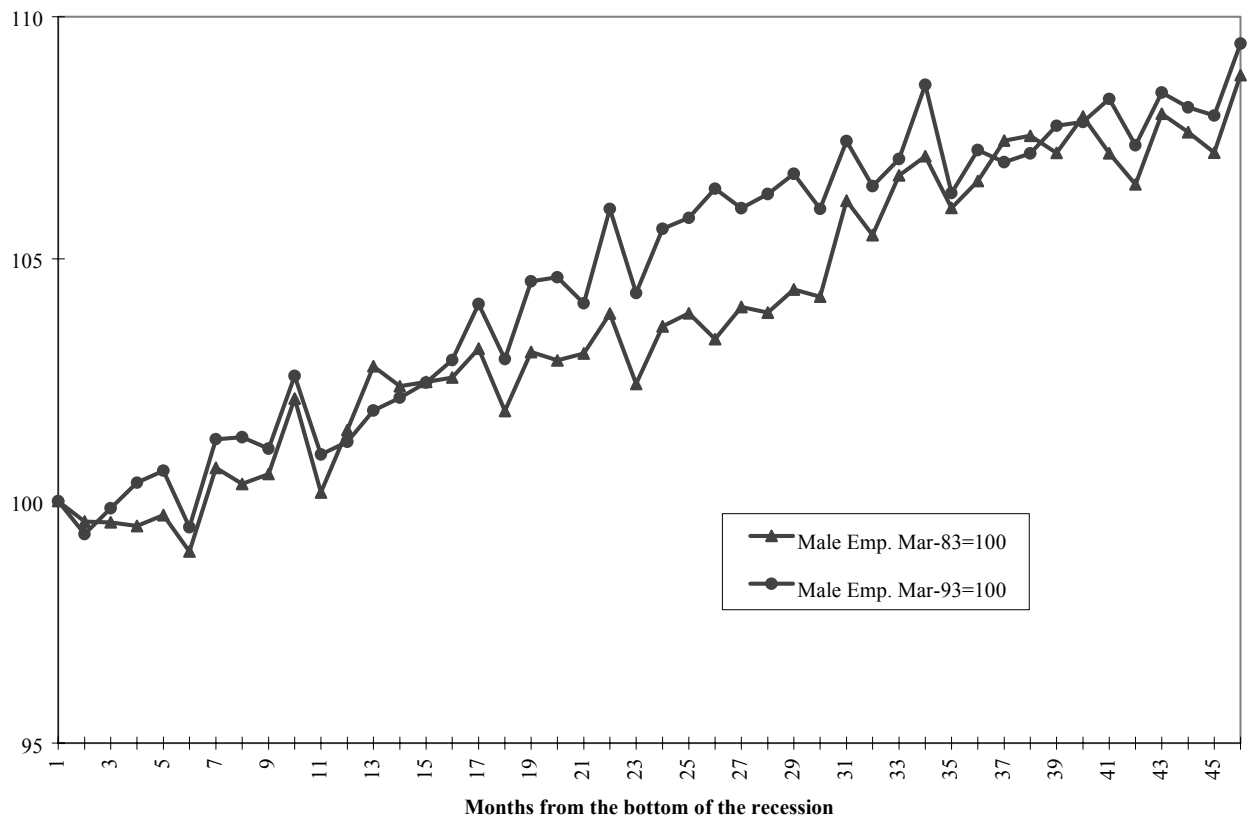

Source: ABS Ausstats.

Figure 4: Female Employment Growth in two cycles, 1983 and 1993

Female Employment Growth in two cycles, 1983 and 1993

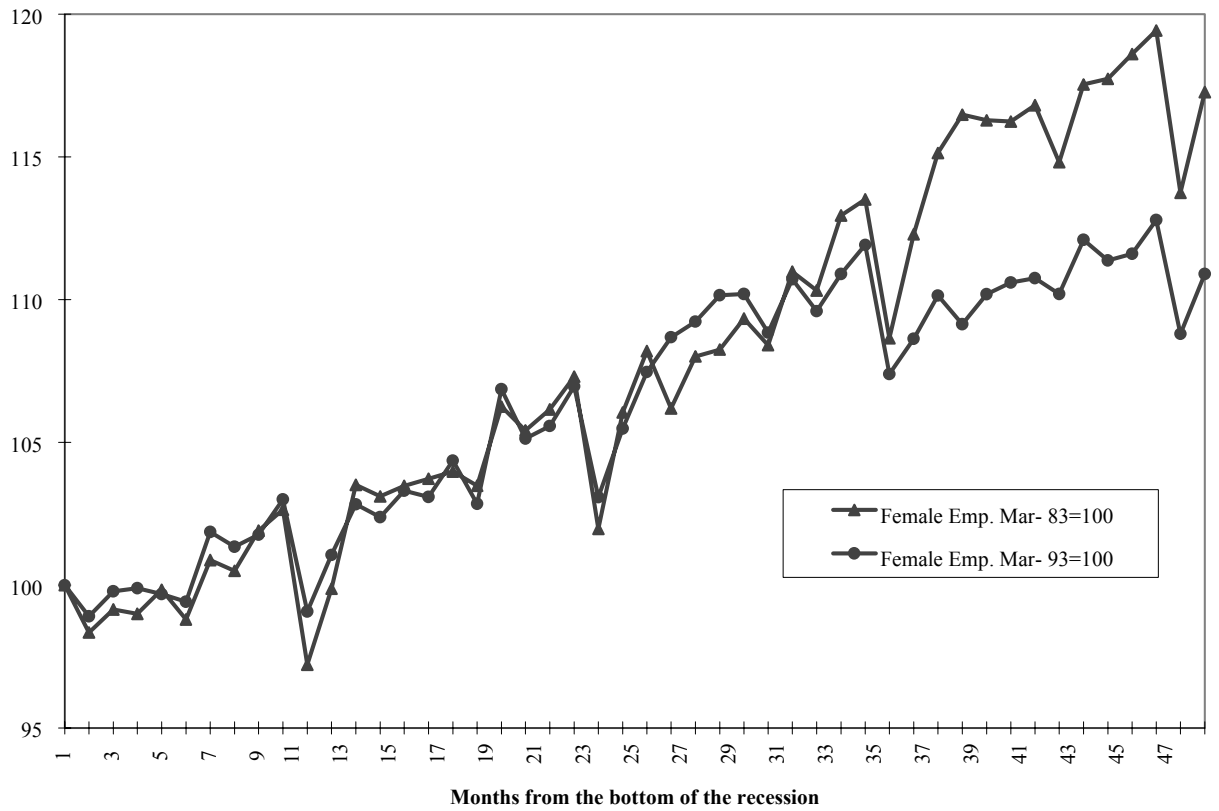

Source: ABS Ausstats. 
Figure 5

Male Unemployment Rate in two cycles, 1983 and 1993

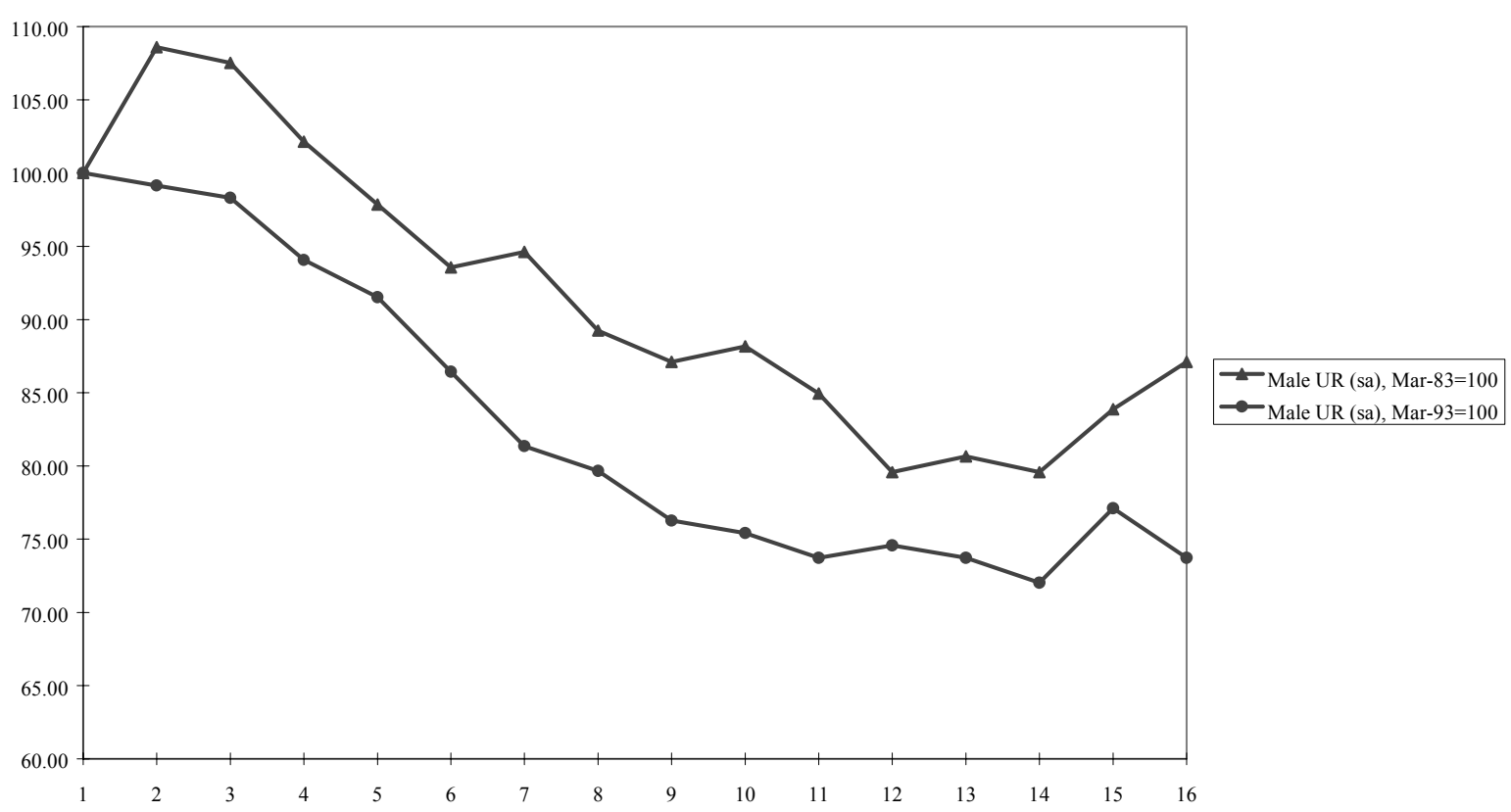

Source: DX data base.

Figure 6

Female Unemployment in two cycles, 1983 and 1993

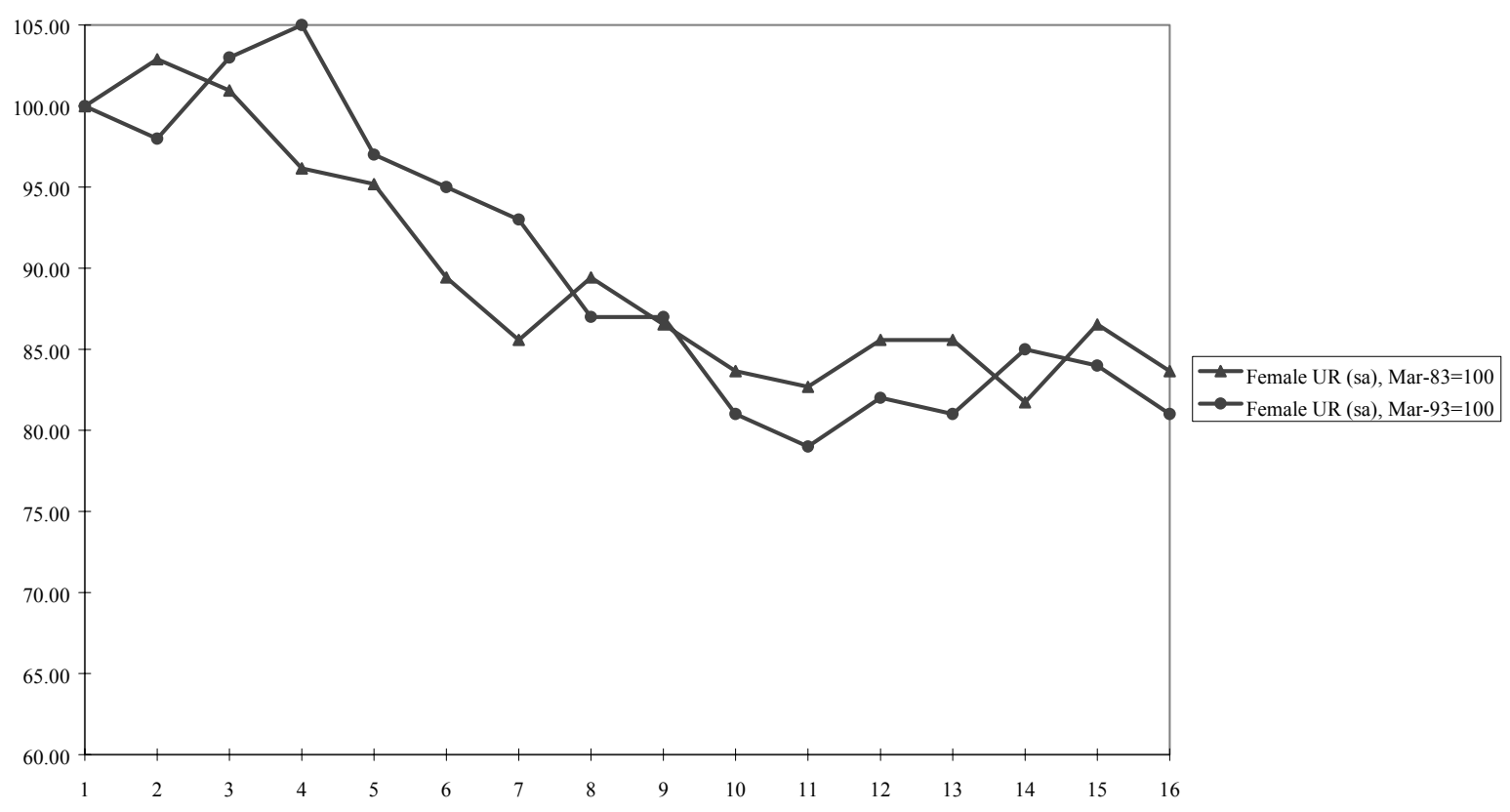

Source: DX data base. 
Figure 7

Proportion of LTU-WN, Males

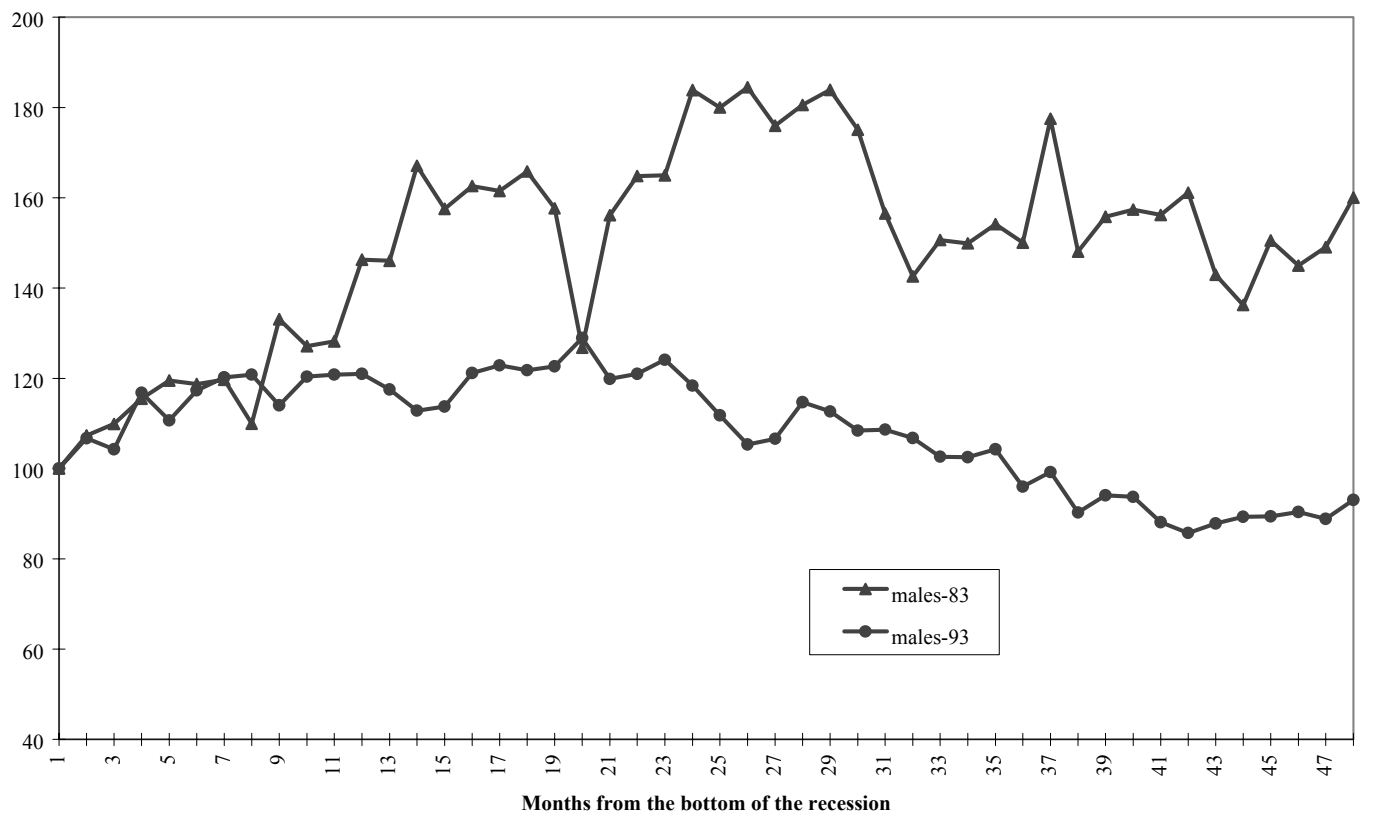

Source: ABS 6203 (unpublished).

Figure 8

Proportion of LTU-WN, Females

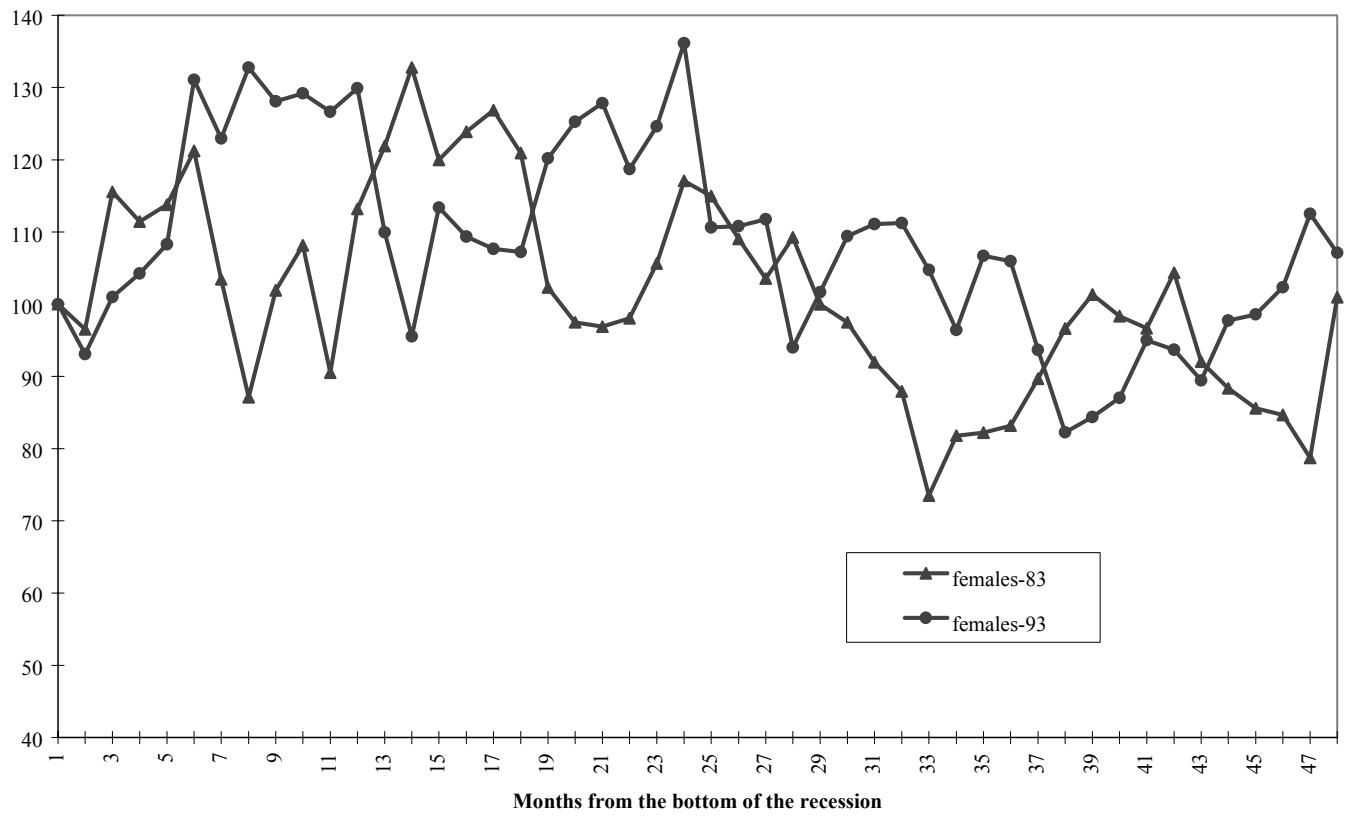

Source: ABS 6203 (unpublished). 


\section{Figure 3: Gross Domestic Product (A) in two cycles, 1983 and 1993}

GDP (A) growth in two cycles, 1983 and 1993

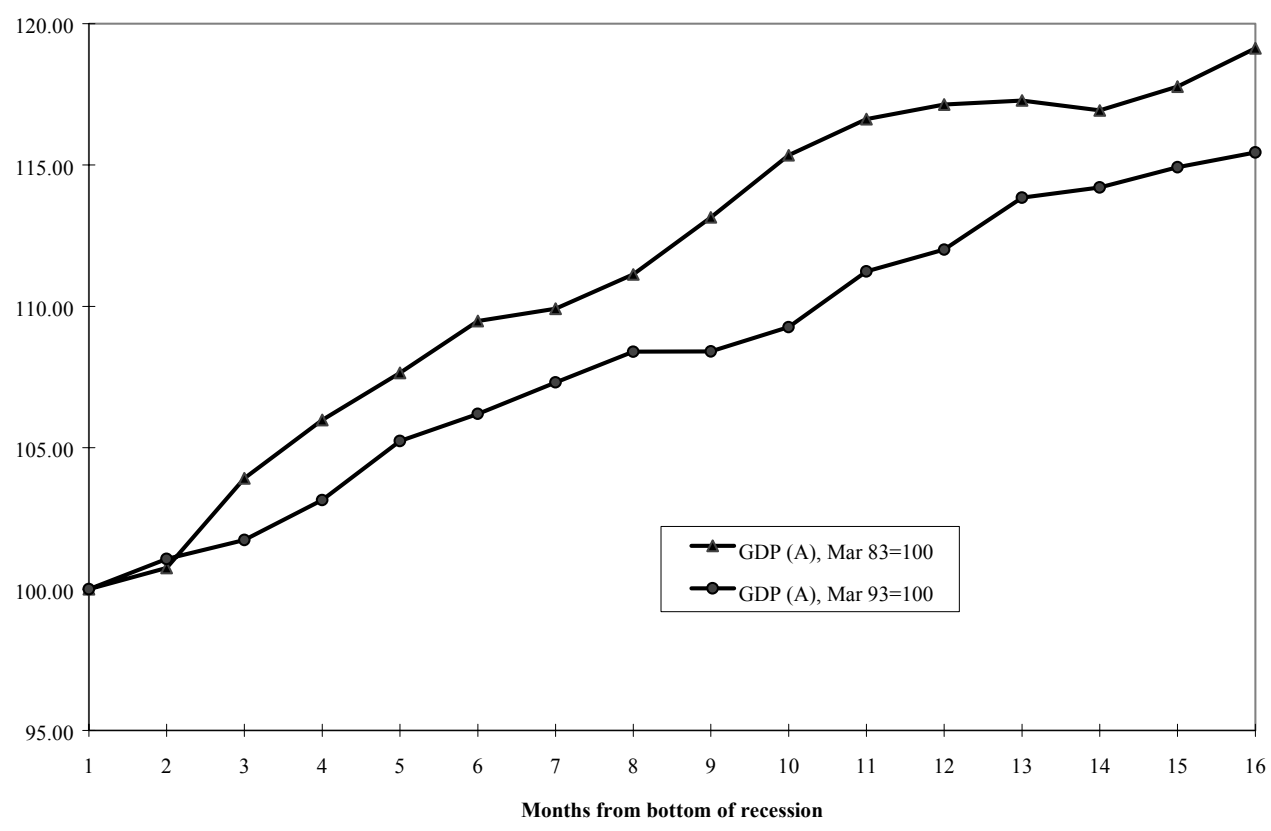


8. LTU Forecasts

Simple model: PLTU depends on lagged unemployment rates and lagged dependent variables.

See Tables 1 and 2.

Our model forecasts compared with actual LTU: We are over-predicting for males after Working Nation, but underpredicting for females.

Figures 13 and 14. 
Figure 13

Males: LTU is 18 months \& over

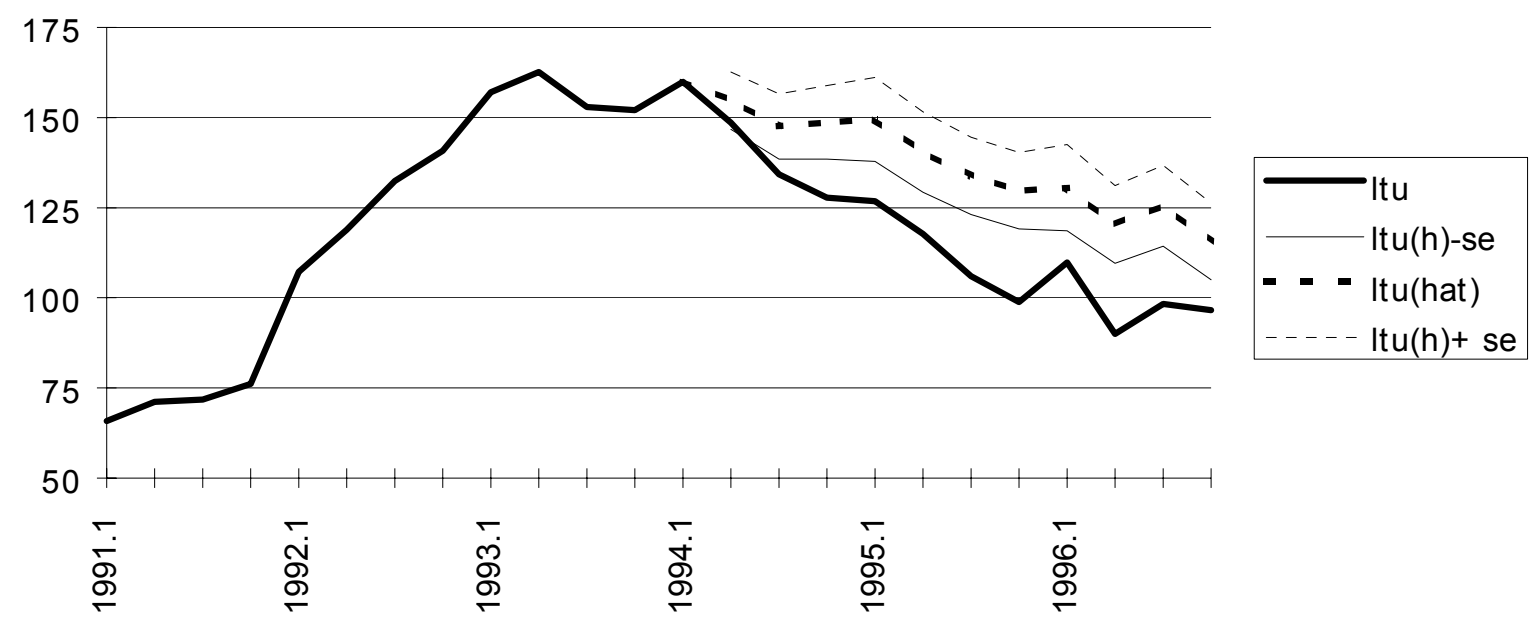

Figure 14

Females: LTU is 18 months \& over

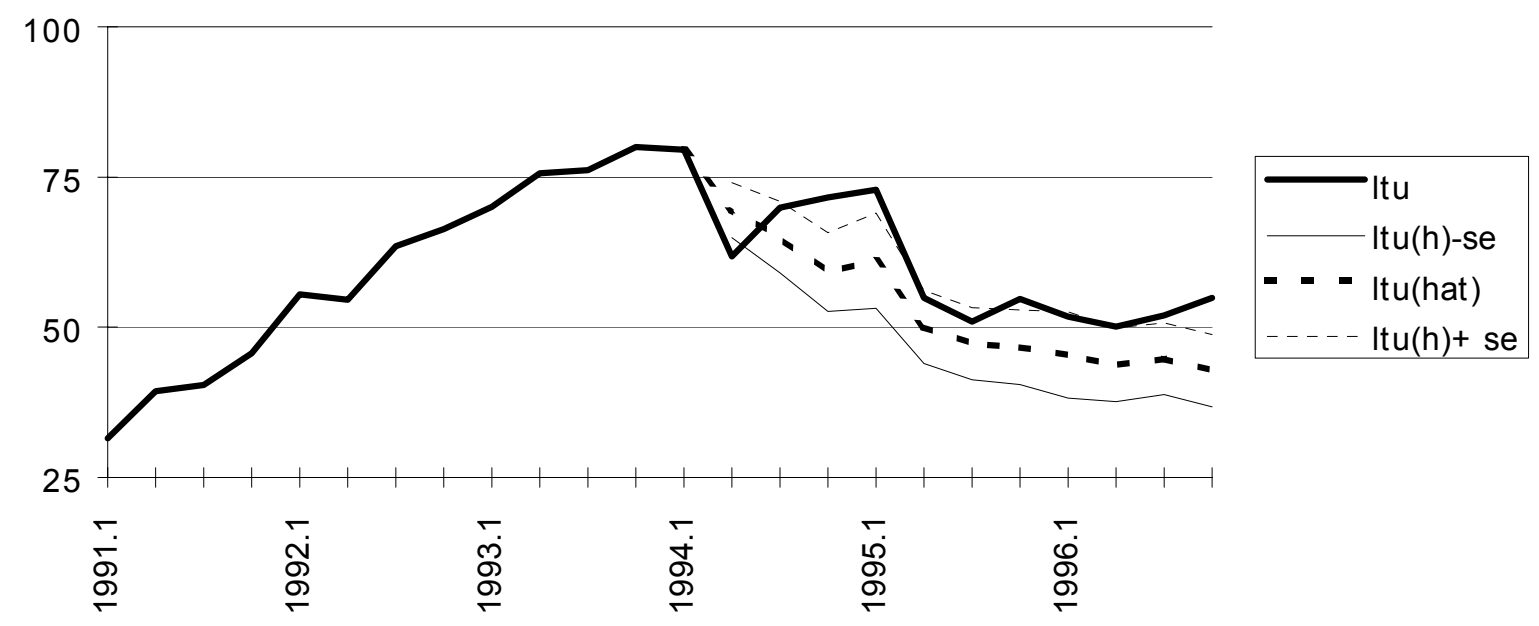


9. Employment

Functions

Estimated simple employment functions for Wage and salary earners using RULC and GDP as regressors, see Russell and Tease (1991).

Usual tests for cointegration, then estimated in log levels. Equation estimates $\mathrm{OK}$.

Employment forecasts: over-predict both for males and females - Why? Change in expectations or Working Nation not working?

Did tight fiscal policy slow down employment?

Figures 16 and 17. 
Figure 16

Wage and salary earners: males

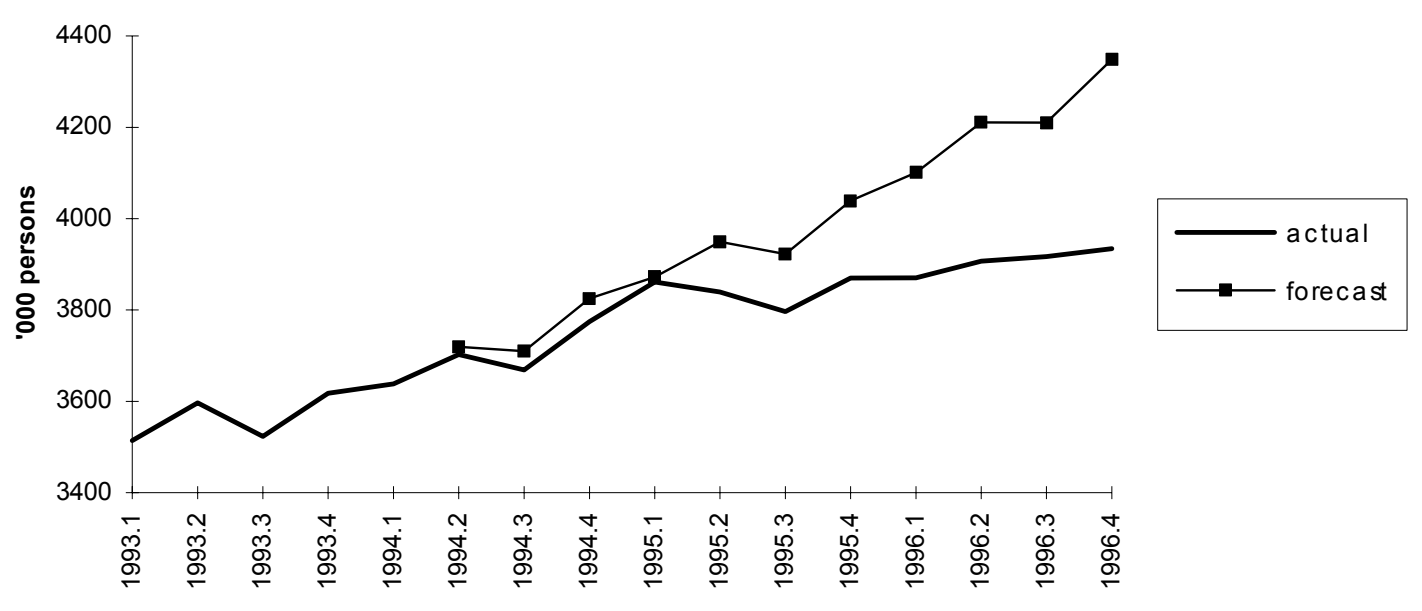

Figure 17

Wage and salary earners: females

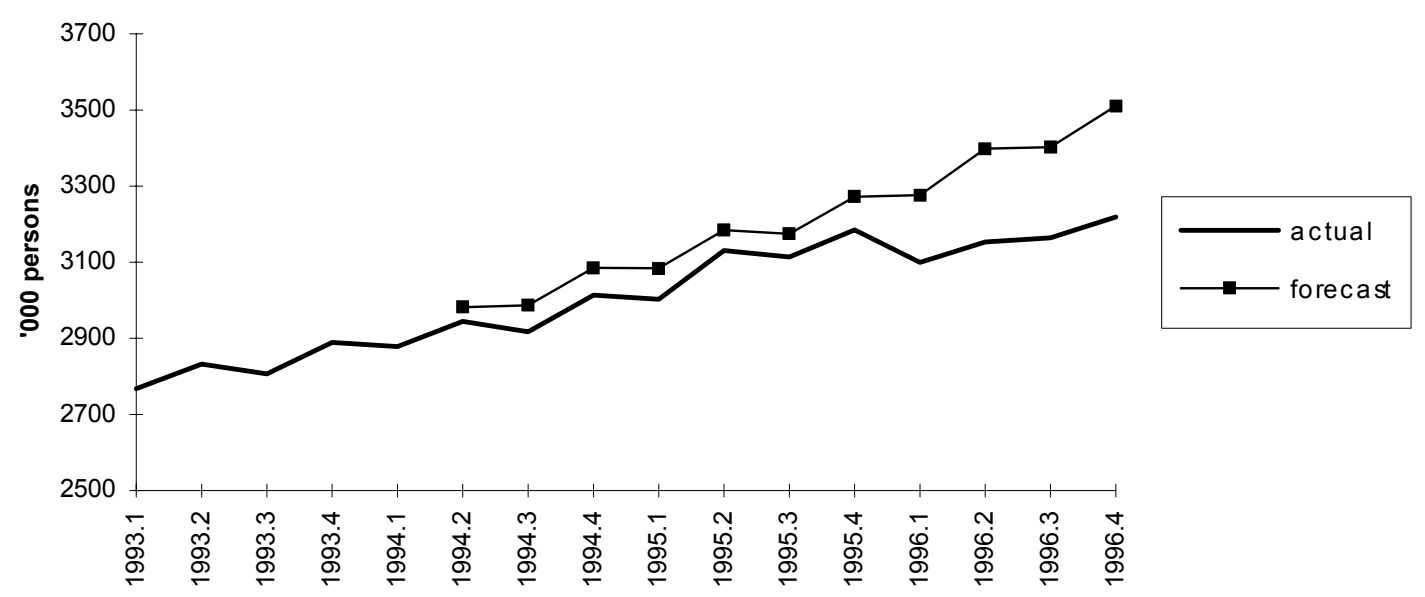


10.

Conclusions

Working Nation has decreased LTU, especially for males but ambiguous about females.

Evidence from employment ambiguous.

Problem with short life of Working Nation, need to run experiment for some time.

Need supportive macro policies to increase demand for labour at same time as labour market programs. 